\title{
Green energy generation by Pressure Retarded Osmosis: State of the art and technical advancement -review ${ }^{1}$
}

\author{
Khaled Touati ${ }^{\mathrm{a} \mathrm{b}^{*}}$

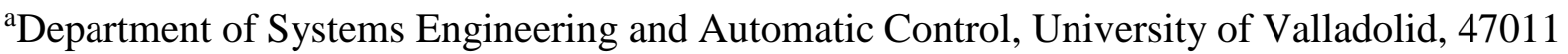 \\ Valladolid, Spain. Tel: +34 983423162; Fax: +34 983423161. \\ ${ }^{b}$ Laboratory of Natural Water Treatment- Water Researches and Technologies Center, \\ Technopark Borj Cedria, BP 273, 8020, Soliman, Tunisia. Tel: + 21679325122 / 79325199 ; \\ Fax: + 216 79325802. *Corresponding author: kha.touati@gmail.com
}

\section{Fernando Tadeo ${ }^{\mathrm{a}}$}

aDepartment of Systems Engineering and Automatic Control, University of Valladolid, 47011 Valladolid, Spain. Tel: +34 983423162; Fax: +34 983423161. fernando@autom.uva.es

\begin{abstract}
:
Pressure Retarded Osmosis (PRO) is a method for converting salinity gradients to power by allowing water to flow through a semi-permeable membrane against an applied hydraulic pressure. PRO already has a long history, starting from the middle of the last century, and has rapidly improved in recent years. In this paper, we present a historical development of PRO since its inception: the development of this renewable energy process has gone through several stages, depending on technological developments, worldwide energy demands, and environmental concerns. The technological progress of the process is also studied, as well as its cost viability and environmental impact. Finally, some ideas to further develop the PRO process and mitigate its detrimental effects are discussed.
\end{abstract}

Keywords: Pressure Retarded Osmosis, Osmotic Power, membranes, Energy cost, Environmental impact.

\footnotetext{
${ }^{1}$ This work was funded by Ministerio de Ciencia e Innovación (Spain) under grant DPI2014-54530-R.
} 


\section{Green energy generation by Pressure Retarded Osmosis: State of the art and technical advancement -review}

\section{Introduction}

The demand of energy is increasing, following economic development and the growth of worldwide population (Chung et al. 2012). In fact, the global primary energy demand has more than doubled since 1971, mainly relying on fossil fuels (IEA, 2014). The world is thus facing unprecedented challenges for energy supply because of the decrease in fossil fuel reserves (Kruyt et al. 2009), aggravated by the emissions of greenhouse gases (GHGs) (Lewis et al. 2011), which generate climate change (Ahiduzzaman et al. 2011). These concerns should provide enough motivation for drastically reducing the use of fossil fuels: Providing affordable, clean, secure, and adequate energy sources remains one of the world's biggest challenges. Therefore, the need for renewable energy sources has increased over the last few years to meet the world energy demand and progressively divert fossil energy sources (Ellabba et al. 2014). Thus, many researchers are focusing on alternative energy sources to fulfill this demand (Post et al. 2007): solar, wind, tidal, wave, and biomass, have been extensively studied to provide secure and sustainable energy sources. Nonetheless, uneven availability of energy sources, complex logistics, or high installation costs are still preventing them from being widely used. This paper concentrates on Pressure Retarded Osmosis, which is an alternative source of renewable energy currently in development: It is part of the so-called Osmotic Power sources, which use the energy generated by differences in salt concentrations between two fluids, commonly fresh and salt water. When a river runs into a sea, spontaneous mixing of fresh and salt water occurs: if the mixing is done reversibly (at least partially), work can be obtained from the mixing process (Post et al. 2007). It is estimated that approximately $0.70-0.75 \mathrm{kWh}$ is dissipated for each cubic meter of freshwater that flows into the sea (Kempener et Neumann 2014), meaning that $1 \mathrm{~m}^{3} \cdot \mathrm{s}^{-1}$ of freshwater can potentially generate up to 2.7 megawatts (MW). The global potential for salinity gradient power is then estimated to be around 647 gigawatts (GW), which is $23 \%$ of electricity consumption (Kempener et Neumann 2014). In fact, Kachan 
\& Co claimed that the osmotic power potential is three times that of solar and wind power generation combined, with the additional advantage of controllability (Kho 2010).

From the Osmotic Power sources, this paper concentrates on Pressure Retarded Osmosis (based on the transport of water through semi-permeable membranes), as it is the most studied and has a large potential for producing energy in different applications (Yip et al. 2013). The purpose of this paper is to present an overview of the PRO evolution and process development, discussing its viability and environmental impact. The expected progress and the main limitations are also discussed.

\section{Pressure Retarded Osmosis}

\subsection{Osmotic processes}

The osmosis phenomenon was observed by Nollet in 1748 (Jamaly et al. 2014). When two solutions of different concentration are separated by a semi-permeable membrane (i.e. one which is permeable to the solvent but impermeable to the solute), osmotic pressure $\pi$ arises due to the difference in the chemical potential. Water flows from the high chemical potential side to the low until equilibrium is reached. The increased volume of water in the low chemical potential side builds up a hydrodynamic pressure difference, which is called the osmotic pressure difference $\Delta \pi$. Osmotic processes include Reverse Osmosis (RO), Forward Osmosis (FO), and Pressure Retarded Osmosis (PRO).

\subsubsection{Reverse Osmosis}

Reverse Osmosis (RO) is a process that uses a semi-permeable membrane to separate and remove dissolved salt from water. It is the process of Osmosis in reverse. Whereas Osmosis occurs naturally without energy required, energy has to be applied to the more saline solution to reverse the process (Cath et al. 2006). A reverse osmosis membrane is a semi-permeable membrane that allows the passage of water molecules. However, the water has to be pushed through the reverse osmosis membrane by applying pressure $\Delta P$ that is greater than the naturally occurring osmotic pressure for pure water to migrate from the saline solution while holding back the majority of the salt (Fig. 1).

\subsubsection{Forward Osmosis}

Forward Osmosis uses the osmotic pressure differential $(\Delta \pi)$ across a semi-permeable membrane, which separates two solutions with different concentrations, as the driving force for 
the transport of water from a low concentrated solution to a high concentrated solution (Fig. 2) (Cath et al. 2006).

\subsubsection{Pressure Retarded Osmosis (PRO)}

Pressure Retarded Osmosis can be viewed as an intermediate process between FO and RO, where hydraulic pressure is applied in the opposite direction of the osmotic pressure gradient (similar to RO). However, the net water flux is still in the direction of the concentrated draw solution (Fig. 1) (Cath et al. 2006).

Fig. 1: Representation of solvent flow in FO, PRO, and RO. Membrane orientation is indicated in each system by the thick black line representing the membrane's active layer.

\subsection{Free Energy of Mixing}

A central concept in Osmotic Pressure is the energy of mixing, which provides an estimation of the non-expansion work that can be produced from mixing. This is theoretically given by Gibbs' free energy: $\Delta_{\text {mix }} G=\Delta H_{\text {mix }}-T \Delta S_{\text {mix }}$, which combines the enthalpy of mixing $\Delta H_{\text {mix }}$, which is a measure of the energy change, and the entropy of mixing $\Delta S_{\text {mix }}$ :

$\Delta_{m i x} G=\Delta H_{m i x}-T \Delta S_{m i x}$

Assuming ideal solutions $\left(\Delta H_{\text {mix }}=0\right)$, the mixing of concentrated and diluted solutions gives (Alvarez-Silva et al. 2015) :

$\Delta_{m i x} G=\Delta G_{b}-\left(\Delta G_{c}+\Delta G_{d}\right)=-\left(n_{c}+n_{d}\right) T \Delta_{m i x} S_{b}+\left(n_{c} T \Delta_{m i x} S_{c}+n_{d} T \Delta_{m i x} S_{d}\right)$

where the subscripts $c, d$ and $b$ correspond, with respect to the concentrated, the dilute and the resulting brackish solutions, $n$ is the number of moles, $T$ is the absolute temperature, and $\Delta_{\text {mix }} S$ is the contribution of the molar entropy of mixing to the total molar entropy of the corresponding electrolyte solution, according to:

$\Delta_{m i x} S=-R \sum_{i} x_{i} \operatorname{Lnx} x_{i}$ 
where $R$ is the gas constant , and $x$ is the mole fraction of component $i$ (for simulated seawater, $i=2)$.

Vermaas et al. (2013) showed that the theoretical Gibbs free energy obtained by mixing simulated seawater (30 g. $\mathrm{l}^{-1}$ of $\left.\mathrm{NaCl}\right)$ and simulated river water $\left(1 \mathrm{~g} . \mathrm{l}^{-1}\right.$ of $\left.\mathrm{NaCl}\right)$ at $1 \mathrm{~m}^{3} . \mathrm{s}^{-1}$ flow rates is 1.39 MJ. Post et al. (Post et al. 2007) completed the results by estimating the theoretically available amount of energy (MJ), presented in Fig.2, from mixing $1 \mathrm{~m}^{3}$ of simulated seawater and $1 \mathrm{~m}^{3}$ of simulated river water for varying concentrations.

Fig. 2: Theoretically available amount of energy (MJ) from mixing $1 \mathrm{~m}^{3}$ of a diluted and $1 \mathrm{~m}^{3}$ of a concentrated sodium chloride solution $(T=293 \mathrm{~K})$. (Post et al. 2007)

\subsection{Basic concept of Pressure Retarded Osmosis}

As has been seen, PRO is a membrane-based process that generates power from salinity gradients (Loeb et al. 1976). The principle of power generation by PRO is illustrated in Fig. 3. When concentrated seawater and diluted fresh water (i.e. river water) are separated by a semipermeable membrane, water will diffuse from the feed side into the draw solution side (i.e. seawater side) that is pressurized: The Gibbs energy of mixing gives the theoretical limit of the energy that can be produced.

To recover the hydraulic energy generated, the resulting pressurized brackish water is then split into two streams: one going through a hydro-turbine to generate electric power, and the other passing through a pressure exchanger to assist in pressurizing the inlet seawater, and thus maintaining the circulation (Skilhagen et al. 2008). The main variables of the process are now discussed in detail.

Fig. 3: Schematic of a PRO power plant.

\subsection{Water and salt fluxes across a PRO membrane in ideal and real cases}

\subsubsection{Ideal membrane with perfect hydrodynamics}

Theoretically, water permeation flux $J_{w}$ across an ideal semi-permeable thin film, which allows water passage but fully rejects all other solute molecules or ions, can be expressed in terms of 
the water permeability coefficient $A$, the osmotic pressure difference $\Delta \pi$, and the transmembrane hydraulic pressure difference $\Delta P$ as follows (Lee et al. 1981):

$$
J_{w}=A(\Delta \pi-\Delta P)=A\left(\pi_{\text {Draw }}-\pi_{\text {Feed }}-\Delta P\right)
$$

where $\pi_{\text {Draw }}$ and $\pi_{\text {Feed }}$ are the bulk osmotic pressures of the draw and feed solutions, respectively. This equation is valid in an ideal system with a perfectly selective membrane (the membrane allows only the passage of water molecules but rejects all solutes) and perfect hydrodynamics in the draw and feed channels, so that the concentrations at the membrane surface are equal to the bulk concentrations.

\subsubsection{Realistic membrane with reverse salt flux and concentration polarization.}

With a realistic membrane and hydrodynamics, an amount of salt permeates the membrane from the draw solution to the feed solution due to the concentration gradient across the membrane, and the effect of hydrodynamics should also be discussed. A schematic presentation of a PRO membrane, at steady state, is shown in Fig. 4. Three phenomena occur to reduce the transmembrane water flux:

i. First, the porous support layer induces the Internal Concentration Polarization (ICP): this effect takes place within the porous support, increasing the local concentration at the active-support interface from $C_{F, m}$ to $C_{i}$, which detrimentally enhances $\pi_{i}$ (the osmotic pressure of the feed solution at the interface active-support layers) by increasing the solute concentration at the feed membrane interface, thus reducing the trans-membrane driving force.

ii. Second, without perfect hydrodynamics in the draw solution flow channel, the dilutive External Concentration Polarization (dilutive ECP) occurs in the mass transfer boundary layer of the draw solution, reducing the local concentration at the active layer from $C_{D, b}$ to $C_{D, m}$, which lowers $\pi_{D, m}$ ( the osmotic pressures of the draw active layer surface membrane). In the feed solution side, the accumulation of the salt at the surface of the support layer leads to the increase of the salt concentration in this location. Therefore, the concentrative ECP appears as a consequence to the increase of feed concentration from $\mathrm{C}_{\mathrm{F}, \mathrm{b}}$ to $\mathrm{C}_{\mathrm{F}, \mathrm{m}}$. This detrimental effect is generally encountered when the feed solution is different from freshwater. 
iii. Lastly, because the membrane is no longer perfectly selective, reverse salt flux takes place, resulting in uncontrolled mixing and therefore reducing the energy extraction in the process.

As consequences of these effects, mass transfer kinetics of water across the semi-permeable membrane under applied hydraulic pressure, $\Delta P$ is more precisely described as:

$$
J_{w}=A\left(\Delta \pi_{m}-\Delta P\right)=A\left(\pi_{D, m}-\pi_{i}-\Delta P\right)
$$

The reverse salt flux, $J_{s}$, is described as (Touati et al. 2015):

$$
J_{s}=B\left(C_{D, m}-C_{i}\right)
$$

where $B$ is the salt permeability coefficient of the membrane active layer and $C_{D, m}$ and $C_{i}$ are the solute concentrations at either side of the active layer. A typical concentration profile through the membrane is shown in Fig. 4.

The salt permeability coefficient $B$ of a semi-permeable membrane can be obtained from RO experiments (Achilli et al. 2009) and is given by:

$$
B=\frac{A\left(1-R_{S}\right)(\Delta P-\Delta \pi)}{R_{S}}
$$

where $R_{S}$ is salt rejection defined as:

$$
R_{S}=1-\frac{C_{P}}{C_{F}}
$$

where $C_{P}$ is the salt concentration in the permeate solution obtained in the RO experiments and $C_{F}$ is that of the feed solution.

The salt reverse flux can be expressed as a function of $J_{w}$ using the van't Hoff factor $\beta$ as (Chou et al. 2012):

$$
J_{S}=\frac{B}{\beta R T}\left(\frac{J_{w}}{A}+\Delta P\right)
$$


Fig. 4: schematic representation of the concentration profile over the membrane, and the directions of the water flux $J_{w}$ and the salt flux $J_{s}$ across a PRO membrane at steady state.

ICP, Concentrative and Dilutive ECP are also shown here.

\subsubsection{Concentration polarization in $P R O$}

Concentration polarization is a phenomenon that can severely reduce the effective osmotic pressure difference across the membrane, due to the accumulation or depletion of solutes near an interface (Tan et al. 2008) As a result of water crossing the membrane, in the PRO process, the solute is concentrated on the feed side of the membrane surface and diluted on the permeate side. Because the membranes used in PRO are typically asymmetric (comprised of a thin dense layer on top of a porous support layer), concentration polarization occurs externally on the dense layer side and internally in the support layer side. Both internal and external concentration polarizations reduce the effective osmotic pressure difference across the membrane.

\section{a. Internal Concentration Polarization}

When a non-ideal composite membrane is operated in a standard PRO process (with the active layer facing the draw solution), water flows from the fresh water through the support and active layers into the draw solution, while salt permeates from the salty water across the membrane skin and the support layer into the fresh water. Therefore, there exists a salt gradient in the membrane support (see Fig. 4). This salt gradient will result in concentrative Internal Concentration Polarization ICP and lower the osmotic force driving the water across the membranes (Chou et al. 2012, Tan et al. 2008).

ICP occurs when the thin film is supported by a porous substrate: based on the mass balance in the porous substrate layer, Lee et al. developed a theoretical model for the PRO process which suggested that membranes with high water permeation and high salt rejection are essential for high PRO performance (Lee et al. 1981). The mass transport of salt in the membrane support, and in each of the boundary layers, will balance the sum of the convective salt transport and the diffusive salt transport due to the gradient in salt concentration. Hence, this balance of transport of salt can be described by:

$$
\frac{\varepsilon D}{\tau} \frac{d C}{d x}-J_{w} C=J_{s}
$$

where $C$ is the salt concentration at position $\mathrm{x}, D$ is the diffusion coefficient, $\varepsilon$ is the porosity 
and $\tau$ is the tortuosity of the support layer. Lee et al. (1981) derived an expression for modeling this phenomenon in PRO, which Loeb et al. (1997) later related to water flux and other membrane constants:

$$
K=\left(\frac{1}{J_{w}}\right) \operatorname{Ln} \frac{B+A \pi_{D, m}-J_{w}}{B+A \pi_{F, m}}
$$

where $K$ is the solute resistivity for diffusion within the porous support layer, defined by:

$$
K=\frac{\tau t_{s}}{\varepsilon D}
$$

where $t_{s}$ is the thickness of the support layer.

\section{b. External Concentration Polarization}

\section{i. Concentrative ECP}

In the PRO process, concentrative ECP occurs when the support layer of the membrane faces the feed solution (Han et al. 2013). The water flow transports the solute from the bulk solution to the surface of the active layer. Water permeates this layer, leaving the solute behind with higher concentrations. Thus, the feed solutes would be expected to accumulate at the surface of the active layer and cause the increase of the feed concentration $\left(C_{F, b} \rightarrow C_{F, m}\right)$ (Fig. 4). The driving force must overcome this increased concentration, in order for the water flux to occur. As a result, the effective osmotic pressure difference would reduce $\left(\pi_{F, b} \rightarrow \pi_{F, m}\right)$. McCutcheon et al. proved that $\pi_{F, m}$ is related to $\pi_{F, b}$ by what is called the concentrative ECP modulus, assuming that the ratio of the membrane surface concentration of feed solute to the bulk concentration is equal to the corresponding ratio of osmotic pressures (McCutcheon et al. 2006):

$$
\frac{\pi_{F, m}}{\pi_{F, b}}=\exp \left(\frac{J_{w}}{k}\right)
$$

where $k$ is the mass transfer coefficient defined as:

$$
k=\frac{S h D}{d_{h}}
$$


where $S h$ is the Sherwood number and $d_{h}$ is the hydraulic diameter of the flow channel. When the feed solution concentration is zero, the concentrative ECP can be considered negligible.

\section{ii. Dilutive ECP}

Dilutive ECP occurs on the draw side of the membrane in PRO mode. It is a phenomenon similar to the concentrative ECP. On the draw side, solutes are diluted at the surface as water enters from the feed side, giving rise to dilutive ECP. As a result, the effective osmotic pressure difference would reduce $\left(\pi_{D, b} \rightarrow \pi_{D, m}\right)$. Dilutive ECP is expressed using the dilutive ECP modulus:

$$
\frac{\pi_{D, m}}{\pi_{D, b}}=\exp \left(-\frac{J_{w}}{k}\right)
$$

\subsection{PRO power density}

In terms of energy production, the power density $W$ is defined as the osmotic energy output per unit of membrane area, which can be calculated by the product of the trans-membrane pressure $\Delta P$ and the water flux $J_{w}$ permeating across the membrane (Loeb et al. 1975):

$$
W=J_{w} \Delta P=A(\Delta \pi-\Delta P) \Delta P
$$

By differentiating Eq. (15) with respect to $\Delta P$, the maximum power density can be obtained. This corresponds to when the hydrostatic pressure difference is equal to half the osmotic pressure difference across the membrane, $\Delta \pi / 2$. Then, the maximum energy that can be produced is:

$$
W_{\max }=A \frac{\Delta \pi^{2}}{4}
$$

Figure 5 shows the variation of the water flux $J_{w}$ and the power density $W$ as a function of $\Delta P$ for FO $(P=0)$ PRO $(\Delta P<\Delta \pi)$, and RO (where $\Delta P>\Delta \pi)$ under ideal conditions. 
Fig. 5: Magnitude and direction of $J_{w}$ for FO, PRO, and RO and magnitude of $W$ for PRO in an ideal case.

\section{Development of PRO}

From our point of view, the development of the PRO process was a result of two fundamental factors. The first one is the membrane fabrication progress, which allows higher values of power density to be reached and proves the feasibility of the process. The second one is the good understanding of the process by developing several mathematical models that imitate the water flux. In this section, a brief description of the history of PRO is presented based on the development of the membranes used in the PRO process and the models developed by researchers since PRO’s inception.

\subsection{Chronological evolution of the PRO process}

Pressure retarded osmosis is a novel technology, although it already has a long history, starting from the first article that was published by Pattle (1954). Since then, the concept of PRO has received spasmodic attention, mainly in the form of design studies and economic viability evaluations. It has not yet been fully developed, due to the inadequate separation capabilities of semi-permeable membranes, the expected high cost, and the relatively low trans-membrane water flux (Skilhagen et al. 2008, Lee et al. 1981, Yip et al 2011). Pattle described how to use osmotic energy and semi-permeable membranes to produce power by mixing freshwater and saltwater in a Nature article, describing that when a volume $V$ of a pure solvent mixes with a much larger volume of a solution of osmotic pressure $\pi$, the free energy released is equal to $\pi V$. No work was then published on PRO for around 20 years.

After the oil crisis in 1973, the subject of renewable energies was opened up, so, from 1974 to 1976, four papers were published about the feasibility of using PRO to produce energy (Loeb et al. 1976, Loeb et al. 1975, Norman et al. 1974). The PRO process subject started to appear as a feasible solution: A schematic diagram of an osmotic energy converter was proposed by Norman et al. (1974). He suggested that freshwater could permeate through a selective permeable membrane into a pressurized seawater chamber, and then the spill-over water could turn a water wheel to power a generator. One year later, Loeb and Norman (1975) proposed PRO based on the osmotic driven membrane process. The first experimental PRO data were published by Loeb at al. (1976), where hollow fiber seawater RO membranes were tested using 
freshwater in bore and pressurized brine in shell. The principle was validated, although the performance was small due to the use of a standard RO membrane.

Loeb and Mehta (1978) published a paper introducing the role of the internal concentration polarization and discussing the strong adverse effect on power generation by PRO. One year later, Loeb and Mehta (1979) published an article investigating various operating conditions to prove the PRO concept and developed a model to predict flux in PRO; they measured power densities of up to $3.27 \mathrm{~W} / \mathrm{m}^{2}$ using a hypersaline draw solution. The result of the study showed a global potential for osmotic power that could produce renewable energy if the design and production of a semi-permeable membrane was addressed for osmotic power. Jellinek and Masuda (1981) proposed the construction of a cost-comparative PRO power plant. Lee et al. (1981) developed a model considering the effect of the internal concentration polarization, while neglecting the external concentration polarization, in order to evaluate the power density and water flux. Low water flux and power density, due to internal concentration polarization of the RO membrane, were obtained in experimental results by Lee et al. and Mehta. Despite this fact, the model developed by Lee et al. (1981) was a reference model for several models developed later. In 1990, a theoretical mechanical efficiency of several configurations of PRO plants was investigated by Loeb et al. It was found that the alternating-flow terrestrial PRO plant had a higher efficiency but required the use of two pressure vessels in addition to the usual PRO equipment. In parallel, Reali et al. (1990) used numerical techniques to compute the profile of salt concentration in the porous support layer in the PRO system showing the effect of membrane characteristics, such as the water permeability coefficient $A$, the salt permeation coefficient $B$, the effective salt diffusivity $D$, and the support layer thickness $t_{\mathrm{s}}$, on the water and salt permeation flux through an anisotropic membrane.

In 1998, Loeb studied the possibility of producing water using the Dead Sea (Loeb 1993): depending on various configurations of the PRO system, the cost of the produced electrical energy would be from 0.058 to $0.07 \$ /$ KWh. During the same year, Seppälä et al. (1999) carried out a theoretical study to optimize PRO. They suggested that the system could be optimized either by maximizing the net power or by maximizing the ratio between the net power and the entropy generation. At the beginning of the 2000s, Loeb continued his investigation on PRO applications, now in the Great Salt Lake, and he found that the cost of produced electrical energy would be $0.15 \$ / K W h$ at this location (Loeb 2000). Then, the pressure exchanger device (originally developed for RO applications) was introduced by Loeb (2002) to reduce internal power consumption, providing a cost-effective PRO system. In 2004, Seppälä published a work 
suggesting that there is no proof that the apparent non-linearity of the osmotic pressure is caused by concentration polarization phenomena (Seppälä et al. 2004).

Since then, the development of osmotic power has been promoted by Statkraft and executed by research groups in Europe, North America and Asia, increasing the power density of the membrane from less than $0.1 \mathrm{~W} / \mathrm{m}^{2}$ up to $3 \mathrm{~W} / \mathrm{m}^{2}$ (Skilhagen 2010). The first prototype PRO installation was opened in Norway by Statkraft in 2009. The plant configuration followed the proposed schematic of Loeb and was designed to generate just $10 \mathrm{~kW}$ of power, to confirm that the designed system can produce power on a reliable $24 \mathrm{~h} / \mathrm{d}$, and as a base for further tests (Statkraft 2009) (see Fig. 6).

In parallel, Achilli et al. (2009) expanded on the model developed by Lee et al. (1981) by considering the external concentration polarization in an experimental and theoretical investigation into the PRO system, and a maximum power density that exceeded $5.1 \mathrm{~W} / \mathrm{m}^{2}$ was observed with a flat sheet cellulose triacetate (CTA) FO membrane. Yip et al. (2011) manufactured a thin film composite PRO membrane with a polysulfone support layer and a polyamide active layer; they also developed a model for the water flux considering internal and external concentration polarizations, and salt flux leakage. Experimental results led to a projected peak power density of $6.1 \mathrm{~W} / \mathrm{m}^{2}$. Since that time, several works have been published on the subject of PRO, studying the parameters to optimize the power density (Achilli et al. 2009, van der Zwen et al. 2012, She et al. 2013, McCutcheon et al. 2007). On the other hand, several membranes have been manufactured for PRO, such as spiral wound membranes and hollow fiber membranes. The progress of the PRO membrane is studied in the coming paragraph. Also, several works investigating the integration of PRO have been published, and this subject is well developed in Section 4.4.

Unfortunately, in 2014, the Statkraft Company declared that it was discontinuing its efforts and leaving the PRO technology development to “other players in the global market”. Hopefully, research into PRO has not been suspended; many researchers are now carrying on the development of the process and improving its performance (Prante et al. 2014, Lin et al 2014, Altaee 2014, Altaee and Hilal 2014). In addition, other interesting PRO projects have been launched, such as “Mega-ton RO-PRO” in Fukuoka City- Japan (Fig. 10) and they have started to publish results (Saito et al. 2012, Tanioka et al. 2012). 
Fig. 6: Schematic diagram of the pilot PRO plant, constructed by Statkraft.

\subsection{PRO models progress}

Detailed models of the process are now being developed in order to understand fully the PRO process, design PRO systems and evaluate their cost and environmental impact. They are briefly reviewed below.

\subsubsection{Loeb model}

The first PRO model was developed by Sidney Loeb (1976) for an asymmetric RO hollow fiber membrane. Loeb considered that the porous substructure has the character of a boundary layer, in which water flux is a function of the concentrations and the concentration gradients. Assuming that the salt flux, $J_{s}$, is negligible, the transport of water in the porous substructure is by diffusion only, the concentration is proportional to the osmotic pressure, and there is no external concentration polarization. The expression of the water flux he developed was:

$$
J_{w}=A\left(\pi_{\text {Draw }}-\pi_{\text {Feed }} \exp \left(\frac{\Delta X}{D_{s p}}\right)-\Delta P\right)
$$

where $\pi_{\text {Draw }}$ and $\pi_{\text {Feed }}$ are the osmotic pressures of the draw and feed bulks, respectively, $\Delta X$ is the thickness of the membrane, and $D_{s p}$ is the diffusion coefficient in the support layer.

\subsubsection{Lee model}

The model developed by Lee et al. (1981) was the first to consider concentration polarization in PRO. Assuming that the external concentration polarization has been reduced to negligible levels by efficient stirring, and the ratio of salt concentrations is equal to the ratio of osmotic pressures, they derived an expression to model the effect of internal concentration polarization in PRO described by Eq. (18):

$$
J_{w}=A\left[\pi_{D, m} \frac{1-\frac{C_{F, b}}{C_{D, m}} \exp \left(J_{w} K\right)}{1+\frac{B}{J_{w}}\left[\exp \left(J_{w} K-1\right)\right]}-\Delta P\right]
$$


where $\pi_{D, m}$ is the osmotic pressure at the active layer in the draw bulk side, $C_{F, b}$ and $C_{D, m}$ are, respectively, the concentration of the feed solution and the solute concentration in the active layer of the draw bulk side, and $K$ is the solute resistivity. The effect of the ICP corresponds to the term $\exp \left(J_{w} K\right)$ in the water flux equation.

\subsubsection{Achili model}

Achili et al. (2009) expanded on the model developed by Lee et al. (1981) by considering the external concentration polarization. Using the external concentration polarization modulus developed in (McCutcheon et al. 2006), and assuming that $C_{F, b} / C_{D, m}=\pi_{F, b} / \pi_{D, m}$, Eq. (18) becomes:

$$
J_{w}=A\left[\pi_{D, b} \exp \left(-\frac{J_{w}}{k}\right) \frac{1-\frac{\pi_{F, b}}{\pi_{D, b}} \exp \left(J_{w} K\right) \exp \left(J_{w} / k\right)}{1+\frac{B}{J_{w}}\left[\exp \left(J_{w} K-1\right)\right]}-\Delta P\right]
$$

where $k$ is the mass transfer coefficient.

\subsubsection{Yip model}

Previously developed models did not take into consideration the effect of the reverse salt flux. In 2011, Yip et al. (2011) modified the existing Lee model to incorporate the effect of ECP and the reverse permeation of the salt. Assuming that the osmotic pressure is linearly proportional to the salt concentration, and neglecting the concentrative ECP, the water flux expression is:

$$
J_{w}=\left(\frac{\pi_{D, b} \exp \left(-\frac{J_{W}}{k}\right)-\pi_{F, b}\left(J_{w} K\right)}{1+\frac{B}{J_{W}}\left[\exp \left(J_{W} K\right)-\exp \left(-\frac{J_{w}}{k}\right)\right]}-\Delta P\right)
$$

where $\pi_{D, b}$ and $\pi_{F, b}$ are the osmotic pressures of the draw and feed bulks, respectively, and $k$

is the mass transfer coefficient in the draw water side. The term $\exp \left(-\frac{J_{w}}{k}\right)$ sums up the effect of the external concentration polarization. The effect of the reverse permeation of the salt is represented by the denominator of Eq. (20).

\subsubsection{Sivertsen model for a hollow fiber PRO membrane}

The previous models are only applicable to flat sheet membranes, and should be modified according to the new spatial parameters when the geometry of the membrane changes. For 
example, Sivertsen et al. (2012) developed a model for water transport in PRO asymmetric hollow fiber membranes. A structure parameter similar to the one for flat sheet membranes has been defined. Assuming a cylindrical geometry of a single hollow fiber, the equation describing the effective concentration difference in the active layer is presented as:

$$
\Delta C_{\text {skin }}=\frac{C_{s}-C_{f}\left(r_{0}+d_{s / r_{0}}\right)^{J v m r_{0} / D}\left(r_{0}-\Delta x_{m e m} / r_{0}-\Delta x_{m e m}-d_{f}\right)^{J v m r_{0} / D}\left(r_{0} / r_{0}-\Delta x_{m e m}\right)^{J v m r_{0} / D \phi}}{\left.\left(r_{0}+d_{S} / r_{0}\right)^{J v m r_{0} / D}+(B / J v m)\left(\left(r_{0}+{ }^{d_{S} / r_{0}}\right)^{J v m r_{0} / D}\right)\left(r_{0}-\Delta x_{m e m} / r_{0}-\Delta x_{m e m}-d_{f}\right)^{J v m r_{0} / D}\left(r_{0} / r_{0}-\Delta x_{m e m}\right)^{J v m r_{0} / D \phi}{ }_{-1}\right]}
$$

where $\Delta C_{\text {skin }}$ is the concentration difference of salt over the membrane's active layer, and $C_{s}$ and $C_{f}$ are the draw and feed bulk solute concentrations, respectively. $J_{v m}$ is the volume flux, $d_{s}$ and $d_{f}$ are the film thicknesses at the draw side and the feed side, respectively. D is the diffusion coefficient, $\Delta x_{\text {mem }}$ is the membrane thickness, $\phi$ is the porosity and $r_{0}$ is the radial distance between the center of the hollow fiber and the active layer.

\subsubsection{Touati model}

The aim of this model is to introduce a general mass transport model which can describe the transport process without any simplification, taking into account all the mass transfer of a PRO, the external boundaries, as well as the active and support layers of an asymmetric membrane, independently of their effect on the process performance. Based on the convection-diffusion theory, Touati et al. (2015) developed a model for the water flux as follows:

$J_{w}=A\left[\left(\pi_{D, b}+\frac{B}{A}\left(1+\frac{A \Delta P}{J_{w}}\right)\right) \exp \left(-\frac{J_{w}}{k_{D}}\right)-\left[\pi_{F, b}+\frac{B}{A}\left(1+\frac{A \Delta P}{J_{w}}\right)\right] \exp \left(J_{w} K\right) \exp \left(\frac{J_{w}}{k_{F}}\right)-\Delta P\right]$

where $k_{D}$ and $k_{F}$ are the mass transfer coefficients in the draw and feed boundary layers, respectively.

\subsection{PRO membranes development}

The earlier studies on PRO were developed using reverse osmosis membranes. Severe internal concentration polarization was found due to the thick support layer, which leads to a very low permeate flow rate. The development of a specific PRO membrane is now a necessity to overcome the limitations of the process. Suitable membranes are being developed following the information extracted from the mathematical models to improve the energy production. 
It must be pointed out that the current rapid progress in FO membranes is opening up new perspectives for the development of PRO membranes. Pressure retarded osmotic and forward osmosis are similar techniques, but differ in the purpose of each process: PRO is generally used to produce energy and FO to produce freshwater.

The best characteristics of membranes for PRO should be:

High density of the active layer for high solute rejection; a thin membrane with minimum porosity of the support layer for low ICP, and therefore, higher water flux.

$>$ Hydrophobicity for enhanced flux and reduced membrane fouling.

$>$ High mechanical strength to sustain hydraulic pressure.

Two main families of membranes are being developed for PRO: flat-sheet membranes and hollow-fiber membranes. Several studies carried out to improve the performance of both membrane families are now discussed.

\subsubsection{Flat-sheet membrane development}

\section{a. Cellulose acetate membrane}

Cellulose acetate (CA) is the most important synthetic cellulose ester. It was first prepared in 1865 by heating cotton with acetic anhydride (Starbard 2009). Cellulose acetate-based membranes have been used widely in the PRO process for power generation (Achilli et al. 2009, Bui et al 2014, Kim et al 2013). These membranes have several advantages, such as high hydrophilicity, which promotes water flux and reduces membrane fouling, as well as providing good mechanical strength and relatively high tolerance to chlorine (Wang et al 2012). The hydrophilic nature of cellulose acetate is desirable in osmotically driven membrane processes: wetting the membrane reduces ICP and increases the water flux (McCutcheon et al. 2008). Based on the Preferential Sorption-Capillary Flow Model, Loeb and Sourirajan (1961) developed a cellulose acetate membrane for seawater desalination. The announcement of LoebSourirajan's membrane in 1960 opened up the golden era of R\&D activities on membrane technologies. During the 1990s, a special membrane for FO was developed by Osmotek Inc. (Albany, Oregon) (Hydration Technologies Inc. (HTI)). This membrane has been tested in a wide variety of applications by different research groups (Achilli et al. 2009, Beaudry et al. 1990, Cath et al. 2005). It is also used successfully in commercial water purification applications for military, emergency relief, and recreational purposes. The HTI membrane revealed a good performance in PRO bench scale tests (Achilli et al. 2009). However, Statkraft, the first PRO prototype plant, obtained in practice power densities of less than $1.5 \mathrm{~W} / \mathrm{m}^{2}$ using 
these conventional cellulose acetate flat sheet membranes (Thorsen et al. 2009). This value is far below the target power density of $5 \mathrm{~W} / \mathrm{m}^{2}$ for the process to be commercially viable. Schiestel et al. (2012) developed a cellulose acetate membrane with a better performance than the HTI membrane, with highly porous support layers with a pressure stability up to 20 bar (Fig. 7). Table 1 presents some experimental results using flat sheet -based cellulose acetate membranes.

Fig. 7: Scanning Electron Microscope (SEM) photos of Cellulose Acetate PRO membrane developed by Schiestel 2012.

\section{b. Thin film composite PRO membrane}

Thin-film composite (TFC) membranes usually consist of layers of dissimilar materials joined together to form a single membrane. This layered construction permits the use of material combinations that optimize the performance and durability of the membrane. Unlike CTA membranes, TFC membranes are characterized by a wide range of feed $\mathrm{pH}$; however, they have a low tolerance to oxidants and chlorine chemicals (Xie et al. 2012). Yip et al. (2011) were the first to use a Polysulfone (PSF)-Polyamide TFC membrane supported by mesh spacers in PRO bench scale tests. The study of the membrane revealed that a less porous sponge-like morphology is present in the top skin portion of the PSF support layer that is capable of minimizing the detrimental effects of ICP, while allowing the formation of a polyamide layer that possesses high water permeability and salt rejection properties. The active layer (modified polyamide Surface) was characterized by a sponge-like skin layer forming on top of a layer containing macrovoids. Yip claimed that the presence of macrovoids is capable of minimizing the ICP; however, this suggestion was rejected by other researchers (Widjojo et al. 2011, Zhang et al 2013). Han et al. (2014) prepared a new modified surface single layer TFC membrane with the so-called "Matrimid” support layer. The membrane revealed a good robustness, high water permeability and sufficient power density. Zhang et al. (2013) fabricated a Polyamide /Polyacrylonitrile (PAN) composite membrane with enhanced mechanical properties and water permeability for osmotic power (Fig. 8). It was shown that the membrane treatment by alcohol leads to higher water fluxes and mechanical stability. Also, ethanol treatment swells up the polymeric chains and extracts unreacted monomers and low molecular weight polymer chains. Consequently, a thinner and smoother polyamide layer with a larger free volume is therefore 
produced, which leads to a higher water flux, better mechanical stability and greater power density. For the first time, Song et al. (2013) introduced the use of nanofiber TFC in PRO power production. The membrane was characterized by an optimized support layer to reduce the effect of ICP. At lab-scale, experiments were carried out using 1.06M NaCl and $80 \mathrm{mM} \mathrm{NaCl}$ solutions as draw and feed solutions to a achieve a power density equal to $15.2 \mathrm{~W} / \mathrm{m}^{2}$. Bui et al. (2014) also tested nanofiber TFC membranes in PRO power production. Two different selective layers were formed, each from different precursors and having different permselectivity. One was generated from Trimesoylchloride (TMC) and m-phenylene diamine (MPD) (mTFC), while the other was produced from Isophthaloyl chloride (IPC) and Polyethyleneimine (PEI) (PTFC). These membranes employ an extremely thin selective layer forming on a highly porous, interconnected, low tortuosity nanofiber mat electro-spun onto a nonwoven polyester backing. This nanofiber structure is tiered, meaning the nanofibers decrease in diameter as they approach the selective layer. Both the pTFC and mTFC membranes exhibited much higher water fluxes and power densities than the HTI-CTA membrane. Some experimental results using flat sheet TFC membranes are presented in Table 1.

Fig. 8: SEM cross-section of the Polyamide/polyacrylonitrile (PAN) substrates made from two polymer concentrations developed by Zhang et al. (2013).

\subsubsection{Hollow fiber PRO membrane}

A hollow fiber membrane is a tubular, self-supporting membrane with a fiber diameter of less than $500 \mu \mathrm{m}$ (Clausi et al 2000). These membranes are prepared by phase inversion in a hollow fiber spinning setup. A viscous polymer solution (dope solution) is pumped through a spinneret and the bore solution fluid is pumped through the inner tube of the spinneret. After a short residence time in air or a controlled atmosphere, the fiber is soaked in a coagulation bath. As with the flat sheet membranes, the hollow fiber membranes have shown a remarkable development since their first use in the PRO process. Hollow fiber membranes were used for the first time in PRO by Chou et al. (2012). The support layer of the membrane was a commercial polymer, polyethersulfone (PES), and the active layer was prepared using polyamide. According to Chou et al., the membrane performance was the best in terms of energy production and mechanical strength as compared to results published for other types of PRO membranes. One year later, Chou et al. (2013) introduced another hollow fiber PRO 
membrane by adopting Polyetherimide as the material for the substrate layer and the RO-like polyamide as the active layer. The newly developed TFC hollow fiber membrane was characterized by a high mechanical strength, high power density and low reverse salt diffusion. Han et al. (2014) fabricated a robust hollow fiber membrane support for high performance thinfilm composite PRO membranes. Han et al. claimed that the desirable hollow fiber supports should possess high stretch resistance and acceptable ductility. The developed TFC PRO hollow fiber revealed a very low specific reverse salt flux value. A fundamental study of polyamidebased thin film composite hollow fiber membranes over a PES support for PRO through chemical modification was carried out by Ingole et al. (2014). The characterization of the membrane revealed that a thinner and smoother polyamide layer with a larger free volume was produced, which led to a higher water flux, better mechanical stability and greater power density than the existing membrane. A thin-film composite TFC hollow fiber membrane via dual-layer co-extrusion technology has been designed and fabricated by Li et al. (2014). The membrane support possesses high burst pressures from 13 to 24 bars. Zhang et al. (2014) used an advanced co-extrusion technology to fabricate the PES hollow fiber supports with diverse structures, from macrovoid to sponge-like. The TFC hollow fiber thus fabricated shows a high asymmetry, high porosity, while a thick skin layer, with a small and narrow pore size distribution underneath the TFC layer, produces a maximum power density of $24.3 \mathrm{~W} / \mathrm{m}^{2}$ at $20.0 \mathrm{bar}$ using $1 \mathrm{M} \mathrm{NaCl}$ as the concentrated brine and deionized water (Fig. 9).

A summary of some experimental results using hollow fiber PRO membranes are illustrated in Table 2.

Fig. 9: SEM of the cross-section and surface morphologies of the PES hollow fiber supports developed by Zhang et al. (2014).

Table 1: Experimental results using flat-sheet PRO membranes under different operating conditions.

Table 2: Experimental results using hollow fiber PRO membranes under different operating conditions.

\section{Integration of PRO with desalination processes (hybrid PRO process)}


The PRO process can be applied to various sources of feed and draw solutions, combinations of freshwater and sea water, pretreated sea water and concentrated brine (SWRO-PRO hybrid process), and effluent and concentrated brine (SWRO-PRO-WWT hybrid process) (Kim et al. 2012). PRO hybridization with desalination technologies, especially FO and RO, was found to be very promising and has the potential of reducing the cost of seawater desalination, as well as the environmental impact of brine discharge to sea (Altaee 2012). In many countries, such as the United States, the combination of the PRO process in conjunction with other types of desalination processes is being actively investigated: the RO-PRO hybrid process is getting the most attention.

In 2010, Japan launched the "Mega-ton water system” (Fig. 10). As part of the project, a prototype RO-PRO hybrid plant was built and operated. Pure water and concentrated brine were supplied from a regional sewage treatment facility and sea water desalination (sea water reverse osmosis (SWRO) plant as feeds for the PRO Toyobo hollow fiber modules. Studied by Saito et al. (2012), the prototype PRO plant got the maximum output power density, $13.8 \mathrm{~W} / \mathrm{m}^{2}$ at a 30 bar hydraulic pressure difference and a 38\% permeation of pure water into the brine. Saito et al. tested the possibility of decreasing the concentration polarization by increasing the orifices of the membrane module. Typically, there are 3 module open ports: namely, the feed inlet, the concentrated brine outlet, and the permeate outlet. The number of open ports in the Toyobo hollow fiber module was increased from 3 to 4 . The fourth port, which was used for feed water discharge, decreased the effect of internal concentration polarization by enhancing the flushing away of leaked salt from the membrane surface.

Fig. 10: Schematic of Mega-ton RO-PRO hybrid.

In another study carried out by Feinberg et al. (2013), a theoretical comparison of the RO-PRO and RO-RED systems was performed. However, this study only considered the thermodynamically reversible PRO and did not consider effects due to concentration polarization and pressure drops along the membrane module. An investigation was presented by Kim et al. discussing four RO-PRO hybrid configuration systems for power generation and seawater desalination using different salinity gradient resources (Kim et al. 2013). The different cases studied are illustrated in Fig. 11. According to Kim et al., RO and PRO are operated for different purposes (to produce water and energy, respectively) and a proper criterion is required 
to compare the different processes. Thus, Kim et al. introduced a new indicator, called the water and energy return rate (WERR), as:

$$
W E R R=\text { Price }_{\text {Electiricity }}\left(W_{P R O}-W_{R O}\right)+\text { Price }_{\text {Water }} Q_{p, R O}
$$

where Price Electiricity $_{\text {and Price }}$ Water are the electricity and water prices, respectively, $W_{P R O}$ and $W_{R O}$ are the energy generated by PRO and the energy consumed by RO, respectively, and $Q_{p, R O}$ is the RO permeate flow. The WERR unit is \$/min. A higher WERR value indicates a higher benefit obtained by the hybrid processes. Based on a previously validated RO process model and a modified model of a pressure-retarded osmosis PRO process to properly consider the spatial distribution of concentration and velocity based on a mass balance principle, Kim et al. claimed that hybrid systems that use seawater as their feed water for RO are more energy price sensitive. Also, the decrease in the size of an RO plant decreases the WERR value, while the size of a PRO plant has no significant impact on the WERR value.

Fig. 11: Schematic of four RO-PRO hybrid systems proposed by Kim et al. (2013).

Achili et al. (2014) investigated the feasibility of a coupled RO-PRO system using a pilot-scale RO-PRO system. Three spiral-wound RO membrane modules were installed in high-pressure vessels in the small-scale pilot system. Each module had an active membrane surface area of $2.8 \mathrm{~m}^{2}$. The membrane modules were arranged in series so that the concentrated brine leaving the first module was the feed solution for the subsequent module. The hybrid system is presented in Fig. 12. A spiral-wound TFC PRO membrane module was used. The module has an active membrane surface area of approximately $4.18 \mathrm{~m}^{2}$ and was installed in a high-pressure vessel in the small-scale pilot system. Seawater is pressurized in a pressure exchanger (PX) before going to the RO system for desalination. In the RO system, the seawater feed splits into two flows: a freshwater permeate and brine concentrate. The pressurized brine concentrate goes first to the Energy Recovery Device (ERD) to reduce its pressure to a desirable level for the PRO process. After leaving the ERD, the brine concentrate enters the PRO system as the draw solution flow, while a feed flow is wastewater effluent. In the PRO module, freshwater permeates across the membrane from the low salinity to the pressurized high salinity stream as a result of the osmotic pressure gradient. A pressure exchanger is installed on the discharge side 
of the diluted draw solution to exchange energy with the seawater feed to the RO membrane system. According to Achili, the RO-PRO system has several advantages: compared to a standard RO-PX system, RO energy consumption is further reduced with energy production by $\mathrm{PRO}$, the brine generated during the RO process is diluted back to seawater concentration. The RO brine is a good draw solution compared to other draw solution sources for three reasons: first, among other readily available draw solutions, RO brine is an abundantly available, lowcost residual from existing commercial systems; second, RO brine has production; and third, the brine entering the PRO subsystem is relatively free of foulants because it receives prior treatment by the RO pretreatment system, which eliminates additional energy expenditure. The energy consumption of the RO membrane system was $3.82 \mathrm{kWh} / \mathrm{m}^{3}$ and $2 \mathrm{kWh} / \mathrm{m}^{3}$, with $20 \%$ and $30 \%$ of recovery, respectively, for without and with ERD, respectively.

Fig. 12: Schematic of RO-PRO hybrid adopted by Achili et al. (2014).

Using the same RO-PRO system as that adopted by Achili, Prante et al (2014) developed a model of the specific energy consumption of an RO-PRO system using RO conditions at the thermodynamic restriction and a novel module-based PRO model. The minimum net specific energy consumption of the modeled system was $1.2 \mathrm{kWh} / \mathrm{m}^{3}$ for $50 \%$ of RO recovery. Under an RO specific energy consumption of $2.0 \mathrm{kWh} / \mathrm{m}^{3}$, the RO-PRO system can theoretically achieve $40 \%$ energy reduction.

Lin et al. investigated a closed-loop system combined membrane distillation (MD), which generates concentrated and pure water streams by thermal separation, and PRO, which converts the mixing energy to electricity through a hydro-turbine (Lin et al. 2014). Fig. 13 shows the different compounds of the PRO-MD hybrid system. Results indicate that the hybrid PRO-MD system can theoretically achieve an energy efficiency of $9.8 \%$ (81.6\% of the Carnot efficiency) with hot and cold working temperatures of 60 and $20^{\circ} \mathrm{C}$, respectively, and a working solution of $1.0 \mathrm{M} \mathrm{NaCl}$. When mass and heat transfer kinetics are limited, conditions that more closely represent actual operations, the practical energy efficiency will be lower than the theoretically achievable efficiency.

Streams S10 and S13 enter the PRO module as the high concentration draw solution and distilled water feed solution streams ("D" and "F" in Fig. 13, respectively) in co-current mode with the draw solution chamber under a constant hydraulic pressure, $p$ PRO. The PRO system generates power when a portion of the exit draw solution stream (S16), at the PRO working 
pressure (pPRO), is depressurized through the hydro-turbine to become S19 at atmospheric pressure $\left(p_{0}\right)$. To maintain continuous operation, a pressure exchanger $(\mathrm{PX})$ is used to change the heightened pressure of S14 to the incoming draw solution stream S8.

Fig. 13: Schematic diagram of a PRO-MD hybrid system for harvesting low-grade heat energy adopted by Lin et al. Heat exchanger (HX). Pressure exchanger. (PX) turbine (TB). (Lin et al. 2014).

Altaee et al. (2014) proposed an integrated PRO-RO system for power generation and seawater desalination (Fig. 14) .Different feed and draw water solution concentrations were studied. Results show that the increase in the feed solution concentration leads to a decrease of the permeate flow rate. Moreover, the study shows that a higher permeate flow rate was achieved through increasing the draw solution flow rate, while increasing the feed solution flow rate had a negligible impact on the permeate flow rate. However, the increase of the draw solution flow rate increases the concentration of $\mathrm{RO}$ and the power consumption without any tangible improvement in the system performance. Another configuration was investigated by Altaee and Hilal (2014), including Forward Osmosis and Pressure Retarded Osmosis. Two configurations were adopted: PRO-FO and FO-PRO systems, as shown in Fig. 15, using a hyper-saline solution and wastewater effluent as the draw and feed solutions respectively. The study showed that the efficiency of the PRO-FO design is higher than that of the FO-PRO design in terms of the power generation. They also tested the effect of the feed solution flow rate, and the results revealed that its effect on the performance of the FO membrane was negligible.

Fig. 14: Schematic diagram of the PRO-RO system for combined power generation and seawater desalination adopted by Altaee et al. (2014)

Fig. 15: Schematic diagram of the FO-PRO system for combined power generation and water treatment desalination adopted by Altaee and Hilal (2014). 
Touati et al (2014) investigated the feasibility of coupling PRO with the multi-effect distillation process (MED) to produce fresh water and energy. The study was based on exploiting the hot brine coming up from the MED, which can improve the performance of the PRO. The hot brine issuing from the desalination unit is used to raise the temperature of the feed water of the PRO (municipal wastewater) using a heat exchanger. Results show that increasing the temperature leads to a better performance of the process. Increasing the temperature will lead to a change in the physiochemical properties of both the membrane and the solution, which can directly influence the osmotic membrane's performance. The result can be justified by the fact that the change in the physical parameters of the two streams, caused by the rise in temperature, improves the water flux crossing the membrane. In fact, the rise in temperature reduces the viscosity of the water at the surface of the membrane and increases the diffusivity of the water. Around $10 \%$ of the energy can be recovered at $40^{\circ} \mathrm{C}$, compared with $7 \%$ at $20^{\circ} \mathrm{C}$. The extrapolations showed that more than $14 \%$ of the energy can be recovered at a high brine temperature $\left(60^{\circ} \mathrm{C}\right)$.

Figure 16: Basic Concept of the Pressure-Retarded Osmosis process for osmotic energy recovery of MED brines proposed by Touati et al. (2014).

He et al. (2014) investigated the feasibility of a reverse osmosis desalination system powered by a stand-alone salinity driven pressure retarded osmosis technology (Fig. 17). A Feasible Condition number (FC) was introduced to study the feasibility of the system. The FC equation takes into consideration the efficiency of all the components in the hybrid RO-PRO:

$$
F C=\frac{\Delta P_{P R O}\left[(1-Y)\left(\eta_{H T}-\frac{\eta_{E R D}}{\eta_{H P}}\right)+Y_{P}\right]}{\Delta P_{P R O}\left[\frac{1-\eta_{E R D}(1-Y)}{\eta_{H P}}\right]}
$$

where $\eta_{H P}, \eta_{E R D}$ and $\eta_{H T}$ are the efficiencies of HP, ERD, and HT, respectively. Y is the RO water recovery. A high value of the FC means a better feasibility of the system. Results show that a lower RO water recovery and a higher ratio of the PRO feed volumetric flow rate to the combined PRO feed and draw flow rates improve the stand-alone feasibility of the hybrid system and the feasible range of the dimensionless water permeation. A higher applied hydraulic pressure, but a lower membrane area, is required to achieve the optimum FC numbers 
at the lower dimensionless water permeation rates at the same RO water recovery. However, the study did not take into consideration the effect of the concentration polarization and the salt reverse flux on the performance of the RO-PRO system.

Fig 17: Schematic diagram of an RO-PRO hybrid system adopted by He et al. (2014)

In another study, He et al. (2015) discussed the performance of the two-stage PRO design. Four configurations were studied and compared to a single-stage PRO performance. According to different flow schemes between the two PRO stages in a "TwoPRO", the four configurations are defined as: CDCF, DDDF, CDDF, and DDCF (Fig. 18), in which 'D' and 'F' in each PRO module represent the draw and feed solution flow channels, respectively. Among the configurations, ' $\mathrm{C}$ ' is shortened for the continuous treatment, which means the solution is treated continuously by the two stages; ' $\mathrm{D}$ ' is shortened for the divided treatment, in which the solution is divided before it flows into the first stage and treated separately in each stage. As an example: in the DDCF configuration, the DS solution is divided into two branches and flows into the two stages separately as the high concentration solution. In the case of CDCF, both feed and draw solutions are connected in series and the salinity gradients are continuously treated in two stages. It is noted that, although CDCF has an advantageous energy capacity in all dimensionless flow rates, its magnitudes are different with respect to the dimensionless flow rate. The maximum energy surplus of the CDCF configuration is reached between the dimensionless flow ratios of 0.5 and 0.6. In the DDDF configuration, two streams of the DS and the FS are divided at the beginning and are treated separately by the two PRO modules. It was noted that the performance of the DDDF configuration is worse than that of the singlestage PRO plant in terms of extractable energy.

In the configurations CDDF and DDCF, only one stream, either the draw or feed solutions, needs to be considered in the flow distribution. Results showed that CDDF and DDCF have advantageous energy capacity under fixed dimensionless flow rate as compared to that of the single PRO.

Fig. 18: Schematic diagram of the four possible configurations of the "TwoPRO” process proposed by He et al. (2015) 
Lee et al. (2015) investigated the integration of PRO with a multi-stage vacuum membrane distillation (MVMD) to produce power and freshwater. Fig. 19 shows the configuration adopted by them. The MVMD system employs a recycling flow scheme (MVDM-R) for the continuous production of both distillate water and highly concentrated brine. The concentrated brine that is produced from the MVMD-R system is then used as a draw solution for power generation in the PRO system, and the feed solution was river water. A power density of $9.7 \mathrm{~W} / \mathrm{m}^{2}$ was achieved under feed and draw solution flow rates of $0.5 \mathrm{~kg} / \mathrm{min}$ and a constant hydraulic pressure difference of 13 bars.

Fig. 19: The schematic of the hybrid MVMD-R-PRO system proposed by Lee et al. (2015).

In the same year, the integration of PRO in Membrane Distillation system (MD-PRO) was investigated to produce energy and potable water (Han et al. 2015). The experiments were carried out with synthetic solutions. A TFC (PES) PRO membrane was used to produce $31 \mathrm{~W} / \mathrm{m}^{2}$ using $2 \mathrm{M} \mathrm{NaCl}$ solution as draw solution against fresh water as feed solution. It was found that MD-PRO process may introduce several advantages such as high water recovery rate, huge osmotic power generation, and well-controlled membrane fouling.

Of course thermal desalination processes are still an important factor in desalination market, however, most attention is still given to RO-PRO hybrid system for potable water production. One of the recent research realized revealed that $1.14 \mathrm{kWh} / \mathrm{m}^{3}$ can be generated for a $50 \%$ recovery seawater RO plant, using wastewater as the feed solution in PRO (Wan et al. 2016). Based on pressure exchangers and high pressure pump positions (Fig.20), about 35\% of RO energy consumption can be recovered.

Fig. 20: SWRO-PRO process proposed by Wan et al. 2016

\section{PRO limitations and suggested solutions}

As with other pressure-driven processes, PRO is limited by concentration polarization, reverse salt diffusion, and other factors that reduce the water flux and the membrane durability. These are now discussed.

\subsection{Membrane fouling}


Membrane fouling is caused by the convective or diffusive transport of suspended or colloidal matter or by biological growth (the so-called bio-fouling). An existing fouling layer increases the overall resistance to mass transfer, so the overall performance decreases significantly. In addition, membrane fouling increases pressure loss along the membrane, while rejection is decreased (Fritzmann et al. 2007).

The first study of PRO membrane fouling was carried out by She et al. (2013). The investigation showed the important effect of the bivalent salt flux diffusion on membrane fouling. In fact, the diffusion of calcium and magnesium from the draw solution to the feed solution increases the fouling process, due to the fact that those ions form interactions with organic foulants which enhance the membrane fouling. The increase of the draw solution concentration leads to the increase of the salt diffusion, thus increasing the membrane fouling. In this respect, She et al. claimed that the concept known in RO as "the critical flux" can be used in PRO as "the critical draw solution concentration”.

A study made by W.R. Thelin et al. (2013) shows that water flux decline did correlate against accumulated natural organic matter (NOM) load and was independent of the concentration of NOM in the fresh water feed. Also, it was noted that the rate of flux decline as a function of accumulated NOM load depends on the type of membrane that was applied for the experiments. The study of the effect of the ionic strength revealed that even though it does have an impact on the fouling propensity, the effect of the ionic strength did not explain the differences found in fouling prosperity for different membrane types. Thelin et al. claimed that there is a strong correlation between PRO membrane characteristics and the fouling prosperity. Therefore, Thelin et al. proposed that the mechanism of fouling is due to NOM accumulation within the porous support and cake formation at the surface of the support membrane (Fig. 21). To face the problem of organic fouling, the authors suggested reducing the fouling potential of the feed water by pretreatment, mitigating the fouling propensity of the membrane by improving structural properties and reducing its affinity towards foulants in the feed water, mitigating the development of fouling backwashing and chemical cleaning.

Fig. 21: NOM cake layer formation on the surface of PRO membrane porous layer.

During further work, Yip and Elimelech (2013) studied the effect of natural organic matter fouling (NOM) and backwashing on PRO performance. They claimed that NOM is able to pass 
through the porous layer and become blocked in the active-porous interface. Thus, two cake layers can be formed: i) on the Surface of the support layer, ii) in the active-porous interface. Results revealed that the NOM deposited in the membrane causes severe escalation in the membrane's hydraulic resistance, thus lowering water permeability and detrimentally reducing water productivity in PRO. The study of backwashing shows that it is able to restore a part of the initial membrane performance due to its ability to totally remove the NOM deposited in the active-porous layer (Fig. 22). Chen et al. (2015) investigated the effect of the hydraulic pressure on PRO fouling by gypsum scalants, sodium alginate, and combined foulants using a hollow fiber membrane. The significant alginate fouling was observed under ultrahigh hydraulic pressures ( $\triangle P>18$ bars), whereas the gypsum scaling was inhibited. Results indicated that the reverse salt flux resulted in a faster rate of alginate fouling, but a limited gypsum scaling. Combined fouling was severe with the co-existence of gypsum crystals and alginate under 0 bar. They attributed this behavior to the fact that the fouling could be enhanced by a high reverse salt flux under 18 bars because the reverse sodium ions induced significant concentration polarization near the membrane surface and calcium ions bridged alginate gelation. In the combined fouling experiments, the membranes were conditioned by one of the foulants followed by the other; Chen et al. suggested that such conditioning could increase the rate of combined fouling because of the change in the membrane's surface chemistry. The study of the co-existence of gypsum crystals and alginate under 0 bar led to synergistic combined fouling and resulted in a greater flux decline than the sum of individual fouling. However, under high pressure PRO tests, gypsum-alginate synergistic fouling was not observed, as the increased reverse salt flux inhibited the formation of gypsum crystals. Consequently, Chen et al. concluded that alginate fouling could be the dominant fouling mechanism for both alginate conditioning and scalant fouling, but scalant conditioning and then alginate fouling for PRO processes under 8 bar and 18 bar. Thus, the removal of alginate type foulants from the feed water stream may become necessary for a good PRO performance under high pressures. A recent study revealed that the use of thick feed spacers can be useful to reduce the biofouling of the FO membrane (Valladares et al. 2014). The result can be extended to PRO membranes. Another recent study revealed that membrane fouling can be caused by phosphate salts and silica (Chen et al. 2016). Fouling mitigation was carried out by addition of EDTA. In fact, EDTA complex calcium and magnesium ions, which are able to form a complex with phosphate ions, and inhibits membrane fouling by phosphate salts. In addition, it was shown that the variation of the $\mathrm{pH}$ also provide a solution for fouling and scaling prevention. However, the decrease of $\mathrm{pH}$ under 6.0 can cause membrane fouling by iron oxides. This probability was not 
discussed by the authors. Some relevant studies were realized with FO membranes to reduce the effect of fouling (Han et al. 2012a, Han et al 2012b). These works aim to increase the water flux and decrease the salt passage due to the hydrophilic characteristic of the membrane support layer. The results showed a decrease of ICP, therefore, the increase of the water flux. Such ideas can be extended to power generation applications to enhance PRO membranes performance due to the fact that PRO and FO membranes have similar characteristics.

Fig. 22: Effect of backwashing on reducing NOM fouling in PRO membrane.

\subsection{Membrane scaling}

Scaling of the membrane is caused by the super-saturation of inorganic compounds concentrated on the feed side. Super-saturated salts can precipitate on the membrane surface, building a thin layer that hinders mass transfer through the membrane (Fritzmann et al. 2007). PRO membrane scaling is not yet well studied: only one published paper was found treating this subject. Zhang et al. (2014) investigated the role of membrane scaling in reducing PRO performance. It was found that the chemistries of the feed and draw solutions play a determinant role in membrane scaling. The existence of precursor ions (i.e., $\mathrm{Ca}_{2}^{+}$and $\mathrm{SO}_{4}{ }^{2-}$ ) may trigger the gypsum precipitation because of the migration of these ions from the draw solution to the feed solution by means of salt reverse flux. Hence, the increase in operating pressure leads to the increase in salt reverse diffusion; therefore, the risk of gypsum precipitation increases. Zhang et al. suggested that if scaling precursors can enter the porous support layer, either by convection from the bulk feed solution or by diffusion from the draw solution, the internal concentration polarization of both convected and reverse diffused scaling precursors leads to an elevated saturation index inside the porous support layer, and thus internal scaling. If the bulk feed solution is oversaturated, external scaling can also occur in addition to internal scaling (Fig. 23). As a solution, the authors claimed that the orientation -active layer facing the feed solutioncan reduce the concentration of the scaling precursor. However, it is not clear how this will affect the power density and the overall performance. Moreover, the control of the salt reverse diffusion by providing a good mechanical stability of the PRO membranes can reduce the risk of scaling. 
Fig. 23: PRO scaling mechanisms. The subscript (i) refers to the precursor (i). Zhang et al. (2014)

\subsection{Concentration polarization}

As mentioned before, Concentration Polarization is one of the major factors that affect the performance of the PRO process. Several works had been carried out to study the impact of this phenomenon on the water flux and the power density. It was noted that the concentration polarization depends on the hydrodynamics, the membrane orientation, the membrane design, and the operating conditions (temperature, pressure, solution concentrations, solution composition...etc.). The internal concentration polarization (ICP) is generally more severe than the external concentration polarization (ECP). To reduce the effect of the ICP, it is necessary to build membranes with the thinnest support layer possible. The effect of the ECP can be mitigated by increasing the cross flow velocity and the operating temperature.

\subsection{Membrane deformation}

One of the main causes of reduced performance in the PRO process is the membrane deformation caused by the hydraulic pressure. Some investigations show that the membrane deformation significantly reduces the water flux (She et al. 2013), with some membranes collapsing at high pressures. Using spacers with a high opening size aggravates the membrane deformation. As presented in the previous section, several research groups are working in the development of robust membranes to withstand high pressure. The use of a moderate opening size of a thick spacer can be beneficial to reduce membrane deformation.

\section{PRO energy cost}

Theoretically, PRO can be a competitive source of energy compared to other renewable energies; for example, compared with other forms of ocean energy, osmotic power cost is similar to ocean energy sources, such as tidal energy (Skilhagen 2012). In fact, under a constant supply of feed and draw solutions, osmotic power plants could operate continuously for more than 8000 h annually (24 hours/day, 7days/week) (Merdawi et al. 2014). Experimental results at laboratory scale show a good performance of the technique. However, the cost perspective 
for full-scale PRO power plants is still uncertain due to the absence of large- scale plants to validate cost assumptions. It is therefore only possible to make projections of costs based on current knowledge and suppositions about the development of the key components of these technologies. Key components affecting the capital, operation, and maintenance costs are the membranes (including replacement over the life-time of the project), the pre-treatments and the pumping of water. It has been estimated that membranes would account for up to $30 \%$ of total capital costs because the cost of PRO membranes is 3 times higher than other commercial membranes (Kempener and Neumann 2014). Another study shows that the intake and outfall systems, pre-treatment facilities, and membranes, all combined, would account for around 75\% of the cost (Valladares et al. 2014).

Nowadays, the price of the commercialized membranes is high, so the viability of the process is affected. The current membrane price is around $5 € / \mathrm{m}^{2}$, but perspectives reported that this price would decrease to $2 € / \mathrm{m}^{2}$ within a few years. Fig. 24 shows the decrease of membrane prices from the early 1990's till now. However, the membrane price is not the only factor that should be taken into consideration; its performance and durability should also be considered. Cheap membranes with low durability and performance are not beneficial for the process. As a comparison, Achili et al. (2010) showed that if the membrane durability is up to 10 years, the revenue is almost 10 times that of a membrane of only 1 year of durability. Concerning the membrane's performance, the difference between the membrane costs for a $1 \mathrm{~W} / \mathrm{m}^{2}$ PRO plant and for a $5 \mathrm{~W} / \mathrm{m}^{2} \mathrm{PRO}$ plant would be approximately 500 million\$ for a 20MW capacity power plant, assuming a cost per unit area of installed membrane of $30 \$$.

Another important factor that can affect the energy production price is the power plant capacity. Kleiterp (2012) analyzed the capital and unit energy costs for both 25 and 200MW osmotic power plants in the Netherlands using a membrane output of $2.4 \mathrm{~W} / \mathrm{m}^{2}$. Perspectives revealed that a unit energy cost of $1.21 \$$ / $\mathrm{kWh}$ resulted from the 25MWosmotic power plant analysis, and $1.0 \$ / \mathrm{kWh}$ from the $200 \mathrm{MW}$ plant.

Several studies revealed that energy production is affected by the nature of the sources used. As an example: Tanioka et al. (2012) reported that the energy cost using freshwater vs brine is $0.16 € / \mathrm{kWh}$, whereas Dinger et al. (2012) reported a cost of $0.18 \$ / \mathrm{kWh}$ using freshwater vs seawater.

It should be noted that the cost also depends on the nature of the installation: stand-alone PRO plant cost should be higher compared to hybrid installation. Cost projections for the year 2020 vary between $0.08 € / \mathrm{kWh}$ and $0.15 / \mathrm{kWh}$ (Genné et al. 2011). On the other hand, costs for hybrid installations are estimated to be $0.11 € / \mathrm{kWh}$ [99]. A detailed cost calculation made by 
Stenzel (2012), based on simulations of plants near existing installations in Germany, demonstrate that besides the cost of membranes and pre-treatment of water, the local site conditions are of particular relevance, for example: to what extent can the plant use the already available infrastructure?

Hopefully, the performance of PRO membranes is improving. Researchers are producing membranes with a high performance under bench-scale tests. Without doubt, this improvement will decrease the energy cost due to the considerable contribution of the membrane cost in the energy production cost. The development of desalination processes enhances the development of the PRO process because of the resemblance between the two techniques in terms of theory and components used. Consequently, the development of the desalination process and its equipment (pressure exchangers, spacers, pumps, vessels, etc.) can be useful for PRO with small modifications for process adaptation.

Other important factors are the pre-treatment and pumping: they could require a relatively large amount of energy with a high cost. These costs need to be brought down to make the installations more efficient. Hydro-Quebec Canada and Statkraft concluded a memorandum of understanding with the purpose of reducing these costs.

The energy cost is strongly related to the power density produced using available membranes. In fact, low power densities will require a large membrane surface to overcome the insufficient PRO membrane performance. As an example, for two membranes with achievable power densities of $1 \mathrm{~W} / \mathrm{m}^{2}$ and $5 \mathrm{~W} / \mathrm{m}^{2}$ respectively, the resulting capital costs are, respectively, $\$ 20,000 / \mathrm{kW}$ and $\$ 4000 / \mathrm{kW}$. The International Renewable Energy Agency reports installation costs of onshore wind farms varying from $\$ 1,700$ to $\$ 2,450 / \mathrm{kW} 1063$ [93], whereas Hinkley et al. [94] reports installation costs for solar power in the order of $\$ 6,800$ to $\$ 7,700 \mathrm{~kW}-11064$. Consequently, the capital cost using a membrane power density of $1 \mathrm{~W} / \mathrm{m}^{2}$ is far above those associated with wind and solar powers. Then, osmotic power generation cannot be considered as a competitive source of energy only if the power density of $5 \mathrm{~W} / \mathrm{m}^{-2}$ combined with low membrane cost.

Levelized Cost Of Energy (LCOE) is one of the utility industry's primary metrics for the cost of electricity produced by a generator. It is calculated by accounting for all of a system's expected lifetime costs (including construction, financing, fuel, maintenance, taxes, insurance and incentives), which are then divided by the system's lifetime expected power output (kWh) (U.S. Energy Information Administration 2014). As a financial tool, LCOE is very valuable for the comparison of various generation options. A relatively low LCOE means that electricity is being produced at a low cost, with higher returns likely for the investor. Statkraft estimated that 
the future LCOE for salinity gradient power may fall in the same range as other more mature renewable technologies, such as wind, based on their current hydropower knowledge, general desalination (reverse osmosis) engineering and specific membrane technology (Lewis et al. 2011). Achieving competitive costs will, however, be dependent on the development of reliable, large-scale and low-cost membranes. Statkraft estimated that investment costs will be much higher than other RE technologies, but that capacity factors could be very high, with 8,000 hours of operation annually. A recent study developed by Naghiloo et al. (2015), investigating the feasibility of $25 \mathrm{MW}$ osmotic power plant installation on the Bahmanshir River (Iran), found that the capital cost to build the plant was 117.6 M€ for a net energy production of 138.75 $\mathrm{GWh} / \mathrm{yr}$, assuming an efficiency of 63.3\%. Naghiloo et al. found that modeling results indicate that, for a 15 year return on investment, an annual increase in purchase price of electricity of $10 \%$ and a constant interest rate of $6 \%$, the sale price of electricity should be $0.41 € / \mathrm{kWh}$, quite expensive compared to other renewable sources $(0.09 € / \mathrm{kWh})$. According to Naghiloo et al. (2015), this high price was due to the high capital cost of the intake and outfall system (61.5\% of the cost), and the pre-treatment (28.4\%).

Thus, to make this installation commercially viable, intake and outfall system costs and pretreatment system costs should be reduced. Economic analysis was performed for this PRO plant Project. Unfortunately, obtained showed that construction of this power plants will not be attractive for private sector investors with the market energy prices.

Fig. 24: Decrease of membrane price (Kleiterp 2012).

Table 3: Estimated energy production cost for different PRO power plants.

\section{Environmental impact}

Pressure retarded osmosis is a renewable energy source without any emissions of $\mathrm{CO}_{2}$. Mono nitrogen oxides $\left(\mathrm{NO}_{\mathrm{x}}\right)$ and carbon monoxide (CO) emissions are also absent and the installations are not important sources of noise (Kempener and Neumann 2014). The mixing of seawater and freshwater is a process that occurs in nature all over the world. Interestingly, most rivers around the globe run into the ocean in a city or an industrial area. This means that most 
of the osmotic power potential can be utilized without constructing power plants in natural areas. It was demonstrated in a previous study that the cumulative rejection of the desalination units of brine into the sea can induce bad effects on the local aquatic environment (Fernandez et al 2005, Raventos et al 2006). As shown in the previous section, the PRO process can be coupled to a desalination plant by using the desalination plant's brine as a draw solution. Thus, this brine will be diluted before being released into the sea, which mitigates its effect on nature. On the other hand, in heavily industrialized areas, it is possible that an osmotic power plant can improve the environmental conditions by the use of their rejected brine (Kempener and Neumann 2014). In addition, osmotic power plants are usually described as requiring a relatively small footprint area and can be constructed partly or completely underground and would thus fit very well into the local environment (Kempener and Neumann 2014). The environmental impact of power plants located at the mouths of rivers can be minimized, thereby respecting the ecological conditions of estuaries and rivers. An environmental optimization and pre-environmental impact assessment of an osmotic power plant located at a river outlet has been compensated by a combination of environmental flow requirements for the river and the osmotic power plant and environmental engineering of intake and outlet of brackish water.

However, some studies revealed that a PRO power plant can have a limited effect on the local environment. In fact, like RO plants, the problems of concentration polarization, fouling and scaling require chemical cleaning that affects the properties of the brackish water released into the environment. Hopefully, biological investigations made by Statkraft have shown that there were no impacts of the discharge water on the local benthic communities in the last 3 years (Kleverud et al. 2012). Another study showed that the surface temperature of the water where the PRO brackish water will be released can be slightly affected due to the temperature difference between the discharge and the water at the surface (Staalstrom et al. 2012). Another important environmental impact that should be taken into account is the large amount of fresh water that can be used by PRO power plants. Investigation reports have said that only around $2.5 \%$ of global water is freshwater and only $1.5 \%$ is directly accessible for human uses, while $70 \%$ of it is used for agricultural issues (The United Nations World Water Development, 2009). The intensive use of fresh water for power generation can worsen water scarcity in the future. Fortunately, PRO could reduce global greenhouse gas emissions by 2741 megatons by 2030 under accelerated environmental policies, according to the International Energy Agency. European Union leaders have agreed on a binding target of cutting emissions by $40 \%$ on 1990 levels by 2030 (Francisco et al 2014). Annual coal-fired generation is projected to double from 7,400 TWh in 2006 to 9,500 TWh in 2015 and 13,600 TWh in 2030. Replacing current and 
planned coal-fired power plants with salinity power plants (40\% of energy conversion) could reduce global greenhouse gas emissions by 10 Pg CO2-eq/year ( 1010 tonnes/year). This means a potential reduction of $40 \%$ of current global energy-related greenhouse gas emissions.

\section{Final considerations and Conclusions}

The current paper reviews Pressure Retarded Osmosis as a source of renewable energy that can be part of the solution for energy scarcity due to its ability to generate a controllable supply of power and its low environmental impact. PRO technology is advancing rapidly and has become the interest of several research groups. At a theoretical level, precise mathematical models have been developed to predict the power density, giving a good correlation with experimental results. Experimentally, the technique is advancing with the development of specific membranes. PRO is financially viable when a minimum power density of $5 \mathrm{Wm}^{-2}$ is produced. This value is reachable at laboratory scale, but unfortunately, this minimum power density is not yet accessible for large scale power plants due to the fact that intrinsic PRO membranes are not yet commercialized.

Like any other osmotic membrane process, many manipulation problems can be faced in PRO, such as fouling, scaling and membrane deterioration. For real PRO applications, the PRO membranes should be configured into modules. However, only limited studies have been reported to investigate what kind of membrane modules could achieve high efficiency and power output. The conventional module designs for current water treatments show severe limitations for PRO applications in terms of spacer, internal flow pattern, pressure loss, membrane area, and membrane deformation. In addition, several precautions should be taken to mitigate these problems, such as the optimization of operating conditions and the improvement of the membrane characteristics. More precisely, one of the most important challenges in PRO process is the improvement of membranes. In fact, several studies revealed that the ICP severely reduces the energy produced because it reduces the osmotic pressure difference. The effect of internal concentration polarization is quantified using the structural parameter of the support layer (s), which is dependent on the support layer characteristics (thickness, tortuosity, and porosity). To mitigate the effect of ICP, researches should be focusing in decreasing the membrane thickness, lowering the tortuosity, and increasing the porosity all with maintaining a good mechanical stability because the PRO membranes are subject of high pressure application to prevent membrane deterioration. In addition, the structure of membrane spacers should be optimized to guaranty membrane stability, reduce fouling, minimize the pressure drop and enhance hydrodynamics at the membrane surface. 
At chemical scale, a good choice of draw and feed solutions is a key parameter in PRO process; higher concentration gradients with a greater extractable energy density can improve the feasibility of PRO. Many reports revealed that hypersaline water such as the Great Salt Lake and The Dead Sea represents a source of higher extractable specific energy that may allow systems to overcome the energetic costs of operation and have a significant net energy output. One of the advantages of PRO use is its ability to be integrated in desalination processes. Several researches realized to study the feasibility of PRO integration in desalination industry were discussed in this work. One of the major drawbacks of seawater desalination is the relatively high energy input required compared to conventional fresh water treatment. Theoretical investigations of RO-PRO hybrid systems showed that PRO brings additional power into the system by recovering the energy available from the brine and reduces its salinity which minimizes the environmental impact.

In theory, many reports have focused on the perspectives of the energy cost using PRO: the lack of full-scale PRO power plants in operation makes the estimation of this cost difficult. The studies discussed in this paper report that the energy cost is mainly affected by membrane cost and performance, the plant capacity and location, and the associated cost of pretreatment and pumping. Reducing the energy cost is one of the important challenges to make PRO competitive.

Environmental studies discussed in this paper have revealed that PRO has a low impact. In fact, PRO can be beneficial in reducing the environmental impact of brines rejected by desalination plants.

\section{ACKNOWLEDGMENTS}

This work was co-funded by the seventh framework program, under grant 288145 (H2OCean), within the Ocean of Tomorrow joint call 2011. 


\section{REFERENCES}

Chung, T.S. Li, X. Ong, R.C. Ge, Q.C. Wang, H.L. and G. Han. 2012. Emerging forward osmosis (FO) technologies and challenges ahead for clean water and clean energy applications. Curr Opin Chem Eng 1:246-257.

IEA. 'CO2 emissions from fuel combustion - highlights'. 2014. Retrieved from: https://www.iea.org/publications/freepublications/publication/CO2 Emissions From Fuel Combustion Highlights 2014.

Lewis, A. Estefen, S. Huckerby, J. Musial,W. Pontes, T. and J. Torres-Martinez. 2011. Ocean energy, in: Edenhofer O, Pichs-Madruga R Sokona, Y, Seyboth K, Matschoss P, Kadner S, Zwickel T, Eickemeier P, Hansen G, Schlömer S, von Stechow C (Eds.). IPCC Special Report on Renewable Energy Sources and Climate Change Mitigation. Cambridge University Press, Cambridge and New York, 
Post, J.W. Veerman, J. Hamelers, H- V.M. Euverink, G- J.W. Metzb, S.J. Nymeijerc, K. and JNC. 2007. Buisman. Salinity-gradient power: Evaluation of pressure-retarded osmosis and reverse electrodialysis. J Membr Sci 288:218-230.

Kruyt, B. van Vuuren, D. P. de Vries H.G.M. and H. Groenenberg. 2009. Indicators for energy security, Energ. Policy 37(6):2166-2181.

Ahiduzzaman, M. and AKM. Sadrul Islam. 2011. Greenhouse gas emission and renewable energy sources for sustainable development in Bangladesh. Renew Sust Energ Rev 15:4659- 4666.

Ellabban, O. Abu-Rub, H. and F. Blaabjerg. 2014. Renewable energy resources: Current status, future prospects and their enabling technology. Renew Sust Energ Rev 39:748-764

Kempener, R. and F. Neumann 2014. IRENA Ocean Energy Technology Brief 2.

Kho J. 2010.Osmotic Power: A Primer, Examining the opportunities and risks of making baseload power from osmosis. Kachan \& Co. report.

Vermaas, D.A. Veerman, J. Yip, N.Y. and Elimelech, M. Saakes, M. and K. Nijmeijer 2013. High Efficiency in Energy Generation from Salinity Gradients with Reverse Electrodialysis. ACS Sustainable Chem Eng 1:1295-1302.

Yip, N.Y. and M. Elimelech. 2014. Comparison of Energy Efficiency and Power Density in Pressure Retarded Osmosis and Reverse Electrodialysis. Environ Sci Technol 48 11002-11012.

Alvarez-Silva, O. and A.F. Osorio. 2015. Salinity gradient energy potential in Colombia considering site specific constraints. Renew Energy 74:737-748.

Jamaly, S. Darwish, N.N. Ahmed, I. and S.W. Hasan. 2014. A short review on reverse osmosis pretreatment technologies. Desalination 354:30-38.

Cath, T.Y. Childress, A.E. and M. Elimelech 2006. Forward osmosis: Principles, applications, and recent developments. J Membr Sci 281:70-87.

Loeb, S. Van Hessen, F. and D. Shahaf. 1976. Production of energy from concentrated brines by pressure retarded osmosis, II. Experimental results and projected energy costs. J Membr Sci 1(3):249-69.

Skilhagen, S.E. Dugstad, J.E. and R.J. Aaberg. 2008. Osmotic power-power production based on the osmotic pressure difference between waters with varying salt gradients. Desalination 220:476-482. 
Lee, K.L. Baker, R.W. and HK. Lonsdale. 1981. Membrane for power generation by pressure retarded osmosis. J Membr Sci 8:141-171.

Yip, N.Y. Tiraferri, A. Phillip, W.A. Schiffman, J.D. Hoover, L.A. Chang Kim, Y. and M. Elimelech. 2011. Thin-Film Composite Pressure Retarded Osmosis Membranes for Sustainable Power Generation from Salinity Gradients. Environ Sci Technol 45:4360-4369.

Chou, S. Wang, R. Shia, L. Shea, Q. Tanga, C. and A.G.Fane. 2012. Thin-film composite hollow fiber membranes for pressure retarded osmosis (PRO) process with high power density. J Membr Sci 389:25- 33.

Loeb, S. Titelman, L. Korngold, E. and J. Freiman. 1997. Effect of porous support fabric on osmosis through a Loeb-Sourirajan type asymmetric membrane. J Membr Sci 129:243-249.

Han, G. Zhang, S. Li, X. and T.S. Chung. 2013. High performance thin film composite pressure retarded osmosis (PRO) membranes for renewable salinity gradient energy generation. J Membr Sci 440:108-121.

McCutcheon, J.R. and M. 2006. Elimelech. Influence of concentrative and dilutive internal concentration polarization on flux behavior in forward osmosis. J Membr Sci 284: 237-247.

Loeb, S. and R.S. Norman. 1975. Osmotic power plants. Science 189: 654-655.

Norman, RS. 1974. Water salination: a source of energy. Science 186:350-352.

Pattle, R.E. 1954. Production of electric power by mixing fresh and salt water in the hydroelectric pile. Nature 174:660-660.

Mehta, G.D. and S. Loeb. 1978. Internal polarization in the porous substructure of a semipermeable membrane under pressure-retarded osmosis. J Membr Sci 4:261-265.

Loeb, S. and G.D. Mehta. 1979. A two coefficient water transport equation for pressure retarded osmosis. J Membr Sci 4:351-362.

Jellinek, H.H. and H. Masuda. 1981. Osmo-power. Theory and performance of an osmo- power pilot plant, Ocean Engineering 8:103-128.

Loeb, S. Honda, T. and M. Reali. 1990.Comparative mechanical efficiency of several plant configurations using a pressure-retarded osmosis energy converter. J Membr Sci 51:323-335.

Reali, M. Dassie, G. and G. Jonsson. 1990. Computation of salt concentration profiles in the porous substrate of anisotropic membranes under steady pressure-retarded osmosis conditions. J Membr Sci 48:181-201. 
Loeb, S. 1998. Energy production at the Dead Sea by pressure-retarded osmosis: challenge or chimera?. Desalination 120:247-262.

Seppälä, A. Lampinen, M.J. 1999. Thermodynamic optimizing of pressure-retarded osmosis power generation systems. J Membr Sci 161:115-138.

Loeb, S. 2001. One hundred and thirty benign and renewable megawatts from Great Salt Lake? The possibilities of hydroelectric power by pressure-retarded osmosis. Desalination 141:85-91.

Loeb, S. 2002. Large-scale power production by pressure-retarded osmosis, using river water and sea water passing through spiral modules. Desalination 143:115-122.

Seppälä, A. and M.J. Lampinen. 2004. On the non-linearity of osmotic flow. Exp Therm Fluid Sci 28: 283-296.

Skilhagen, S. 2010. Osmotic power- a new, renewable energy source. Desalination 15:271-278.

Statkraft Press Centre. 2009. Crown princess of Norway to open the world's first osmotic power plant 2009, http://www.statkraft.com/presscentre/press-releases/crownprincess-mettemarit-toopen-the-worlds-first-osmotic-power-plant.aspx.

Achilli, A. Tzahi, Y.C. and A.E. Childress. 2009. Power generation with pressure retarded osmosis: An experimental and theoretical investigation. J Membr Sci 343:42-52.

She, Q. Hou, D. Liu, J. Tan, K.H. C.Y. and Tang. 2013. Effect of feed spacer induced membrane deformation on the performance of pressure retarded osmosis (PRO): Implications for PRO process operation. J Membr Sci 445:170-182.

van der Zwan, S. Pothof, I.W.M. Blankert, B. Bara, J.I. 2012. Feasibility of osmotic power from a hydrodynamic analysis at module and plant scale, J Membr Sci 389:324-333.

Patel, S. 2014. Statkraft Shelves Osmotic Power Project, Power Magazine. http:/www.powermag.com/statkraft-shelves-osmotic-power-project/.

Loeb, S. 1976. Production of energy from concentrated brines by pressure retarded osmosis: I. Preliminary technical and economic correlations. J Membr Sci 1:49-63.

Sivertsen, E. Holt, Thelin, T.W. and G. Brekke. 2012. Modelling mass transport in hollow fibre membranes used for pressure retarded osmosis. J Membr Sci 417-418:69-79.

Touati, K. Hänel, C. Tadeo, F. and T. Schiestel. 2015. Effect of the feed and draw solution temperatures on PRO performance: theoretical and experimental study. Desalination 365:182195. 
McCutcheon, J.R. and M. Elimelech. 2007. Modeling water flux in forward osmosis: implications for improved membrane design. AIChE J 53:1736-1744.

Starbard, N. 2009. Beverage Industry Microfiltration, John Wiley \& Sons 1:47.

Wang, X. Huang, Z. Li, L. Huang, S. Hao, Y.E. and K. Scott. 2012. Energy generation from osmotic pressure difference between the Low and high salinity water by pressure retarded osmosis. $\mathrm{J}$ Technol Innov Renew Energy 1:122-30.

McCutcheon, J.R. and M. Elimelech. 2008. Influence of membrane support layer hydrophobicity on water flux in osmotically driven membrane processes, J Membr Sci 318:458-466.

Loeb, S. and S. Sourirajan. 1961. UCLA Dept. Eng. Report 1:60-60.

Beaudry, E.G. and K.A. Lampi. 1990. Membrane technology for direct osmosis concentration of fruit juices. Food Technol 44:121.

Cath, T.Y. Gormly, S. Beaudry, E.G. Adams, V.D. and A.E. Childress. 2005. Membrane contactor processes for wastewater reclamation in space. I. Direct osmotic concentration as pretreatment for reverse osmosis. J Membr Sci 257:85-98.

Thorsen, T. and T. Holt. 2009. The potential for power production from salinity gradients by pressure retarded osmosis. J Membr Sci 335:103-10.

Schiestel, T. Hänel, C. Öxler, L. Roelofs, K. and E. Walitza. 2012. Cellulose acetate membranes with an optimized internal structure for pressure retarded osmosis. in: Proceedings of the $3^{\text {rd }}$ Osmosis Membrane Summit., Statkraft, Barcelona;.

Widjojo, N. Chung, T.S. Weber, M. Maletzko, C. and V. Warzelhan. 2011. The role of sulphonated polymer and macrovoid-free structure in the support layer for thin-film composite (TFC) forward osmosis (FO) membranes. J Membr Sci 383:214-23.

Zhang, S. Fu, F.J. and T.S. Chung. 2013. Substrate modifications and alcohol treatment on thin film composite membranes for osmotic power. Chem Eng Sci 87:40-50.

Bui, N-N. and J.R. 2014. McCutcheon Nanofiber supported thin-film composite membrane for pressure-retarded osmosis. Environ Sci Technol 48(7):4129-36.

Kim, Y.C. and M. Elimelech. 2013. Potential of osmotic power generation by pressure retarded osmosis using seawater as feed solution: analysis and experiments. J Membr Sci 429:330-37. 
She, Q. Jin, X. and Y. Tang Chuyang. 2012. Osmotic power production from salinity gradient resource by pressure retarded osmosis: Effects of operating conditions and reverse solute diffusion. J Membr Sci 401-402:262-73.

Clausi, D.T. and W.J. Koros. 2000. Formation of defect-free polyimide hollow fiber membranes for gas separations. J Membr Sci 67:79-89.

Chou, S. Wang R. Shi, She, Q. Tang, C. and A.G. Fane. 2012. Thin-film composite hollow fiber membranes for pressure retarded osmosis (PRO) process with high power density. J Membr Sci 389:25-33.

Chou, S. Wang, R. and A. G. Fane. 2013. Robust and High performance hollow fiber membranes for energy harvesting from salinity gradients by pressure retarded osmosis. J Membr Sci 448:44-54.

Han, G. and T-S. Chung. 2014. Robust and high performance pressure retarded osmosis hollow fiber membranes for osmotic power generation, AIChE J 60(3):1107-19.

Ingole, P.G. Choi, W. Kim, K-H. Jo, H-D. Cho, W-K. Park, J-S. and H-K. Lee. 2014. Preparation, characterization and performance evaluations of thin film composite hollow fiber membrane for energy generation. Desalination 345:136-45.

Li, X. and T-S. Chung. 2014. Thin-film composite P84 copolyimide hollow fiber membranes for osmotic power generation. Appl Energy 114:600-10.

Zhang, S. Sukitpaneenit, P. and T-S. Chung. 2014. Design of robust hollow fiber membranes with high power density for osmotic energy production. Chem Eng J 241:457-65.

Straub, A.P, Yip, N.Y. and M. Elimelech. 2014. Raising the Bar: Increased hydraulic pressure allows unprecedented high power densities in Pressure-Retarded Osmosis. Environ Sci Technol Lett 1:55-9.

Xie, W. Geise, M.G. Freeman, B.D. Lee, H-S. Byun, G. McGrath and E. James. 2012. Polyamide interfacial composite membranes prepared from m-phenylene diamine, trimesoyl chloride and a new disulfonated diamine. J Membr Sci 403-404:152-61.

Kim, J. Lee, J. and J-H. Kim. 2012. Overview of pressure-retarded osmosis (PRO) process and hybrid application to sea water reverse osmosis process. Desal Wat Treat 43:193-200.

A. Altaee. 2012. Forward Osmosis, Potential use in desalination and water reuse, J Membr Sep Technol 1:79-93. 
Saito, K. Irie, Zaitsu, M. S. Sakai, H. Hayashi, H. and A. Tanioka. 2012. Power generation with salinity gradient by pressure retarded osmosis using concentrated brine from SWRO system and treated sewage as pure water. Desal Water Treat 41:114-21.

Feinberg, B.J. Ramon, G. and E.M.V. Hoek. 2013. Thermodynamic analysis of osmotic energy recovery at a reverse osmosis desalination plant. Environ Sci Technol 47:2982-89.

Kim, J. Park, M. A-Snyder S, and J-H. Kim. 2013. Reverse osmosis (RO) and pressure retarded osmosis (PRO) hybrid processes: Model-based scenario study. Desalination 322:121-30.

Achilli, A. Prante, J.L. Hancock, N.T. Maxwell, E.B. and A.E. Childres. 2014. Experimental results from RO-PRO: A next generation system for low-energy desalination. Environ Sci Technol 48 (11):6437-43.

Prante, J.L. Ruskowitz, J.A. Childress, A.E. and A. Achilli. 2014. RO-PRO, desalination: An integrated low-energy approach to seawater desalination. Appl Energy 120:104-14.

Lin, S. N.Y. Yip, Cath, Y.T. C.O. Osuji, M. Elimelech. 2014. Hybrid Pressure Retarded Osmosis-Membrane Distillation System for Power Generation from Low-Grade Heat: Thermodynamic Analysis and Energy Efficiency. Environ Sci Technol 48:5306-13.

Altaee, A. Zaragoza, G. and A. Sharif. 2014. Pressure retarded osmosis for power generation and seawater desalination: Performance analysis. Desalination 344:108-15.

Altaee, A. and N. Hilal. 2014. Dual-stage forward osmosis/pressure retarded osmosis process for hypersaline solutions and fracking wastewater treatment. Desalination 350:79-85.

Touati, K. de la Calle, A. Tadeo, F. Roca L, Schiestel, T. D.C. Alarcón-Padilla. 2014. Energy recovery using salinity differences in a multi-effect distillation system. Desal Wat Treat 1-8.

He, W. Wang, Y. Sharif, A. and M. Hasan Shaheed. 2014. Thermodynamic analysis of a standalone reverse osmosis desalination system powered by pressure retarded osmosis. Desalination 352:27-37.

He, W. Wang, Y. and M. Hasan Shaheed. 2015. Enhanced energy generation and membrane performance by two-stage pressure retarded osmosis (PRO). Desalination 359:186-99.

Lee, J-G. Kim, Y-D. Shim, S-M. Im, B-G. W-S. Kim. 2015. Numerical study of a hybrid multistage vacuum membrane distillation and pressure-retarded osmosis system. Desalination, http://dx.doi.org/10.1016/j.desal.2015.01.043. 
Mega-ton Project Enters Final Stage, http://www.desalination.com/wdr/49/16/ mega-ton-projectenters-final-stage; 2014.

Fritzmann, C. Löwenberg, J. Wintgens, T. Melin. 2007. State-of-the-art of reverse osmosis desalination. Desalination 216:1-76.

She, Q. Wong, Y.K.W. Zhao, S. and CY. Tang. 2013. Organic fouling in pressure retarded osmosis: Experiments, mechanisms and implications. J Membr Sci 428:181-89.

Thelin, W.R. Sivertsen, E. Holt, T. G. Brekke. 2013. Natural organic matter fouling in pressure retarded osmosis. J Membr Sci 438: 46-56.

Yip, N.Y. and M. Elimelech. 2013. Influence of Natural Organic Matter Fouling and Osmotic Backwash on Pressure Retarded Osmosis Energy Production from Natural Salinity Gradients. Environ Sci Technol 47:12607-16.

Chen, S.C. Wan, C.F. and T-S. Chung. 2015. Enhanced fouling by inorganic and organic foulants on pressure retarded osmosis (PRO) hollow fiber membranes under high pressures. J Membr Sci http://dx.doi.org/10.1016/j.memsci.2015.01.037.

Valladares Linares, R. Bucs Sz ,S. Li, Z. AbuGhdeeb, M. Amy, G. Vrouwenvelder, J.S. 2014. Impact of spacer thickness on biofouling in forward osmosis. Wat Res 57: 223-33.

Zhang, M. Hou, D. She, Q. and C.Y. Tang. 2014. Gypsum scaling in pressure retarded osmosis: Experiments, mechanisms and implications. Wat Res 48:383-95.

Skilhagen, S.E. 2012. Osmotic power: a new, renewable source of energy, in: Proceedings of the $3^{\text {rd }}$ Annual European Renewable Energy Markets, Platts, Berlin.

Sharif A. O. Merdaw, Alatee, A. Aryafar, M. and P. Nicoll. 2014. Theoretical and Experimental Investigations of the Potential of Osmotic Energy for Power Production. Membranes 4:447468.

Kempener R. and F. Neumann. 2014. Salinity gradient energy technology brief. The International Renewable Energy Agency.

Kleiterp, R. 2012. The Feasibility of a Commercial Osmotic Power Plant. (Masterthesis), Department of Hydraulic Engineering, Delft University of Technology, Delft-The Netherlands.

Achilli, A. and A.E. Childress. 2010. Pressure retarded osmosis: from the vision of Sidney Loeb to the first prototype installation - review. Desalination 261(3):205-11. 
Tanioka, A. Saito, K. Irie, M. Zaitsu, S. Sakai, H. and H. Hayashi. 2012. Power generation by pressure retarded osmosis using concentrated brine from sea water desalination system and treated sewage: review of experience with pilot plant in Japan. in: Proceedings of the $3^{\text {rd }}$ Osmosis Membrane Summit, Statkraft, Barcelona;.

Dinger, F. Troendle, T. and U. Platt. 2012. Osmotic power plants, in: Proceedings of the $3^{\text {rd }}$ Osmosis Membrane Summit, Statkraft, Barcelona.

Genné, I. and E. Brauns. 2011. "Energy Generation and Desalination: The REAPOWER project”, in Lienard F, Neumann F., F. (eds.), Salinity Gradient Power in Europe: State of the Art, Sustainable Energy Week Brussels.

Stenzel, P. 2012. Potentials of the Osmosis for Generating and Storing of Electricity. Energy and Sustainability 4:ISBN: 978-3-643-11271.

U.S. Energy Information Administration, Levelized Cost and Levelized Avoided Cost of New Generation Resources in the Annual Energy Outlook 2014, http://www.eia.gov/forecasts/aeo/index.cfm.

Fernandez, Y-T. Sanchez-Lzaso, J.L. and J.M. Gonzales-Correa. 2005. Preliminary results of the monitoring of the brine discharge produced by the SWO desalination plant of Alicante (SESpain). Desalination;182:395-402.

Raventos, N. Macpherson, E. and A García-Rubiés. 2006. Effect of brine discharge from a desalination plant on macro benthic communities in the NW Mediterranean. Mar Environ Res 62:1-14.

Kleverud, J. Skilhagen, S.E. and G. Brekke. 2012. Experiences with the Tofte prototype plant. in: Proceedings of the $3^{\text {rd }}$ Osmosis Membrane Summit, Statkraft, Barcelona.

Staalstrom, A. and J. Gitmark. 2012. Environmental Impacts by Running an Osmotic Power Plant. Norwegian Institute for Water Research, Report no.6307-2012, Prepared for Statkraft Development AS, Oslo, Norway.

The United Nations World Water Development Report 3: Water in a Changing World; 2009.

Ramon, G.Z. Feinberg, B.J. and E.M.V. Hoek. 2011. Membrane-based production of salinitygradient power. Energy Environ Sci;4:4423-34.

Francisco, G.M. Maria, J.A. and M.A. Francisco. 2014. Renewable energy production in Spain: A review. Renew Sust Energ Rev 33:509-31. 
Naghiloo, A. Abbaspour, M. Behnam, M-I. and K. Bakhtari. 2015. Modeling and design of a 25MW osmotic power plant (PRO) on Bahmanshir River of Iran. Renew Energy 78:51-59.

Naghiloo, A. Abbaspour, M. Behnam, M-I. Ivatloo, B.M. and K. Bakhtari. 2015. GAMS based approach for optimal design and sizing of a pressure retarded osmosis power plant in Bahmanshir river of Iran. Renew Sust Energ Rev 52:1559-1565.

Palacin LG, Tadeo F, De Prada C, Touati K. 2013. Evaluation of the recovery of osmotic energy in desalination plants by using pressure retarded osmosis. Desal and Wat Treat;51(1-3):360-365.

Touati K, Tadeo F, Hänel C, Schiestel T. 2015. Effect of the operating temperature on hydrodynamics and membrane parameters in pressure retarded osmosis. Desalin Water Treat 1-13, http://dx.doi.org/10.1080/19443994.2015.1039600.

Touati K, Tadeo F. 2016. Study of the Reverse Salt Diffusion in pressure retarded osmosis: Influence on concentration polarization and effect of the operating conditions. Desalination 389 : 171-186.

Gang Han, Peng Wang, and Tai-Shung Chung, Highly Robust Thin-Film Composite Pressure Retarded Osmosis (PRO) Hollow Fiber Membranes with High Power Densities for Renewable Salinity-Gradient Energy Generation. Environ. Sci. Technol. 2013, 47, 8070-8077.

Si Cong Chen, Gary L. Amy, Tai-Shung Chung, Membrane fouling and anti-fouling strategies using RO retentate from a municipal water recycling plant as the feed for osmotic power generation. Water Research 88 (2016) 144-155.

Gang Han, Jian Zuo, Chunfeng Wan and Tai-Shung Chung, Hybrid pressure retarded osmosismembrane distillation (PRO-MD) process for osmotic power and clean water generation. Environ. Sci.: Water Res. Technol., 2015, 1, 507-515.

Xiaoxiao Song, Zhaoyang Liu and Darren Delai Sun, Energy recovery from concentrated seawater brine by thin-film nanofiber composite pressure retarded osmosis membranes with high power density. Energy Environ. Sci., 2013, 6, 1199-1210.

Thin-film composite forward osmosis membranes with novel hydrophilic supports for desalination. J. Membr. Sci. 423-424 (2012) 543-555.

G. Han, S. Zhang, X. Li, N. Widjojo and T, S. Chung. Thin film composite forward osmosis membranes based on polydopamine modified polysulfone substrates with enhancements in both water flux and salt rejection. Chem. Eng. Sci. 80 (2012) 219-231. 
Table 1: Experimental results using flat-sheet PRO membranes under different operating conditions.

\begin{tabular}{|c|c|c|c|c|c|}
\hline Membrane & Feed water concentration & Draw water concentration & Pressure (bar) & Power density $\left(\mathrm{W} / \mathrm{m}^{2}\right)$ & References \\
\hline CTA & DI* & $1 \mathrm{M}$ & 9.7 & 5.1 & (Achilli et al. 2009) \\
\hline CTA & $0.04 \mathrm{M}$ & $1 \mathrm{M}$ & 9.7 & 4 & (Achilli et al. 2009) \\
\hline CTA & DI & $1 \mathrm{M}$ & 9.7 & 5.1 & (Achilli et al. 2009) \\
\hline CA & DI & $1 \mathrm{M}$ & 8.2 & 1.6 & (She et al. 2012) \\
\hline CA & $0.1 \mathrm{M}$ & $1 \mathrm{M}$ & 13 & 3.8 & (She et al. 2012) \\
\hline CA & $0.1 \mathrm{M}$ & $2 \mathrm{M}$ & 13 & 6.7 & (She et al. 2012) \\
\hline CA & DI & $1 \mathrm{M}$ & 8 & 2.25 & (Schiestel et al. 2012) \\
\hline CTA & $0.5 \mathrm{M}$ & $1 \mathrm{M}$ & 9.3 & 0.73 & (Kim and Elimelech 2013) \\
\hline CTA & $0.5 \mathrm{M}$ & $2 \mathrm{M}$ & 21.6 & 2.1 & (Kim and Elimelech 2013) \\
\hline TFC & DI & $0.5 \mathrm{M}$ & 12 & 10 & (Yip et al. 2011) \\
\hline Matrimid TFC & DI & $1 \mathrm{M}$ & 15 & 12 & (Han et al 2013) \\
\hline PAN-TFC & DI & $0.6 \mathrm{M}$ & 10 & 2.6 & (Zhang et al. 2013) \\
\hline Matrimid TFC & DI & $0.6 \mathrm{M}$ & 13 & 9 & (Han et al 2013) \\
\hline SiO2/PAN-TNC & $80 \mathrm{mM}$ & $1.06 \mathrm{M}$ & 24 & 15.2 & (Song et al. 2013) \\
\hline PAN-mTFC & DI & $0.6 \mathrm{M}$ & 10 & 8.0 & (Bui et al. 2014) \\
\hline PAN-pTFC & DI & $0.6 \mathrm{M}$ & 8.3 & 6.2 & (Bui et al. 2014) \\
\hline TFC (FO) & DI & $3 \mathrm{M}$ & 48 & 60 & (Straub et al. 2014) \\
\hline
\end{tabular}


*DI: deionized water

Table 2: Experimental results using hollow fiber PRO membranes under different operating conditions

\begin{tabular}{|c|c|c|c|c|c|}
\hline Membrane & Feed water concentration & Draw water concentration & Pressure (bar) & Power density $\left(\mathrm{W} / \mathrm{m}^{2}\right)$ & References \\
\hline PES-TFC & $0.04 \mathrm{M}$ & $1 \mathrm{M}$ & 5.1 & 6.2 & (Chou et al. 2012) \\
\hline Matrimid-TFC & DI & $1 \mathrm{M}$ & 16 & 14 & (Han et al. 2013) \\
\hline PEI-TFC & $0.001 \mathrm{M}$ & $1 \mathrm{M}$ & 15 & 20.9 & (Chou et al. 2013) \\
\hline Matrimid-TFC & DI & $1 \mathrm{M}$ & 15 & 16.5 & (Han et al. 2014) \\
\hline PES TFC & DI & $0.6 \mathrm{M}$ & 6 & 1.62 & (Ingole et al. 2014) \\
\hline P84 TFC & DI & $1 \mathrm{M}$ & 21 & 12 & (Li et al. 2014) \\
\hline Modified PES-TFC & DI & $1 \mathrm{M}$ & 20 & 24.3 & (Zhang et al. 2014) \\
\hline $\begin{array}{c}\text { PBI/POSS- } \\
\text { PAN/PVP dual- } \\
\text { layer }\end{array}$ & $10 \mathrm{mM}$ & $1 \mathrm{M}$ & 15 & 5.1 & (Fu et al. 2014) \\
\hline
\end{tabular}

*DI: deionized water 
Table 3: Estimated energy production cost for different PRO power plants.

\begin{tabular}{|c|c|c|c|}
\hline Feed solution & Draw solution & Energy cost $(\$ / k W h)$ & References \\
\hline RO Desalination brine & brine from Dead sea & 0.07 & (Loeb 1998) \\
\hline river water & brine from Great Salt Lake & 0.09 & (Dinger et al. 2012) \\
\hline freshwater & seawater & 0.18 & (Skilhagen 2012) \\
\hline freshwater & seawater & $0.09-0.16$ & (Tanioka et al. 2012) \\
\hline freshwater & brine from desalination & 0.16 & (Sharif et al. 2014) \\
\hline freshwater & seawater & $0.07-0.12$ & (Stenzel 2012) \\
\hline freshwater & seawater & 0.045 & (Stenzel 2012) \\
\hline freshwater & brine from desalination plant & 0.13 & (Kleverud et al. 2012) \\
\hline freshwater & seawater & 0.33 & (Naghiloo et al. 2015) \\
\hline freshwater & seawater & $0.13-0.26$ & \\
\hline river water & Persian Gulf & 0.47 & \\
\hline
\end{tabular}




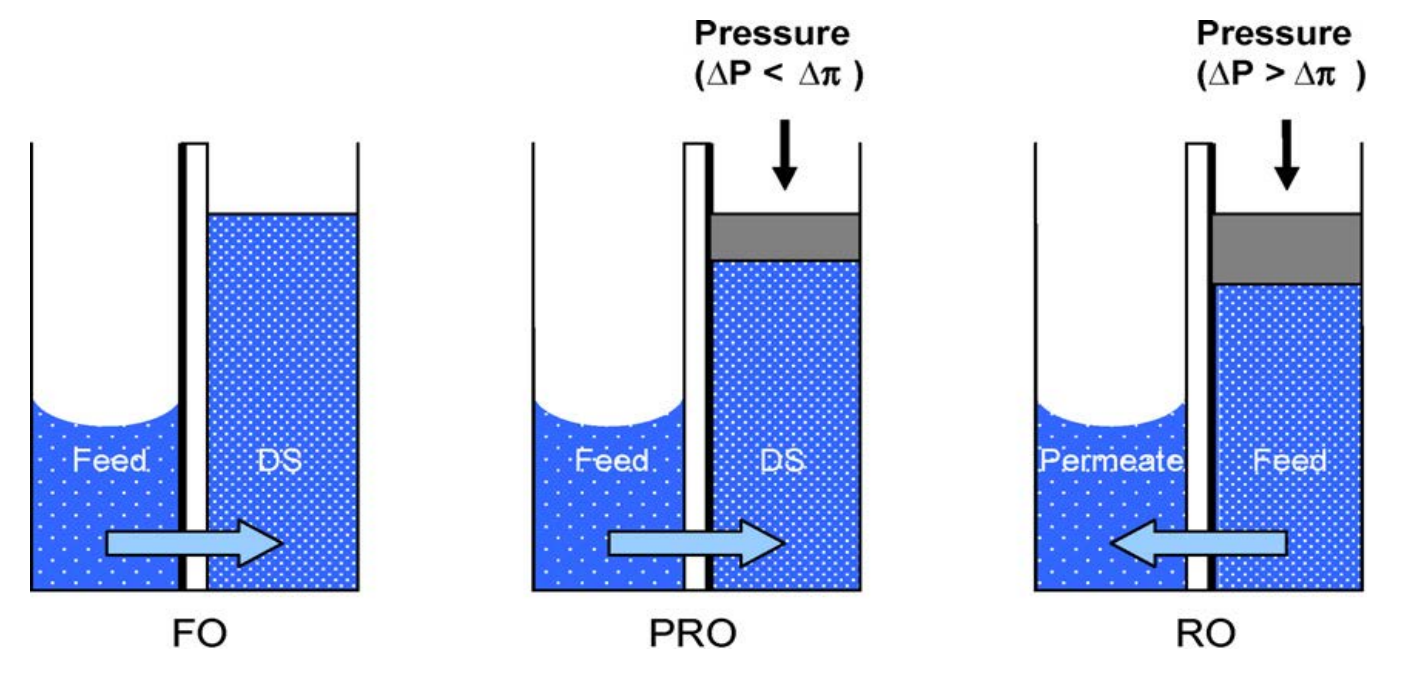

Fig. 1 Representation of solvent flow in FO, PRO, and RO. Membrane orientation is indicated in each system by the thick black line representing the membrane's active layer.

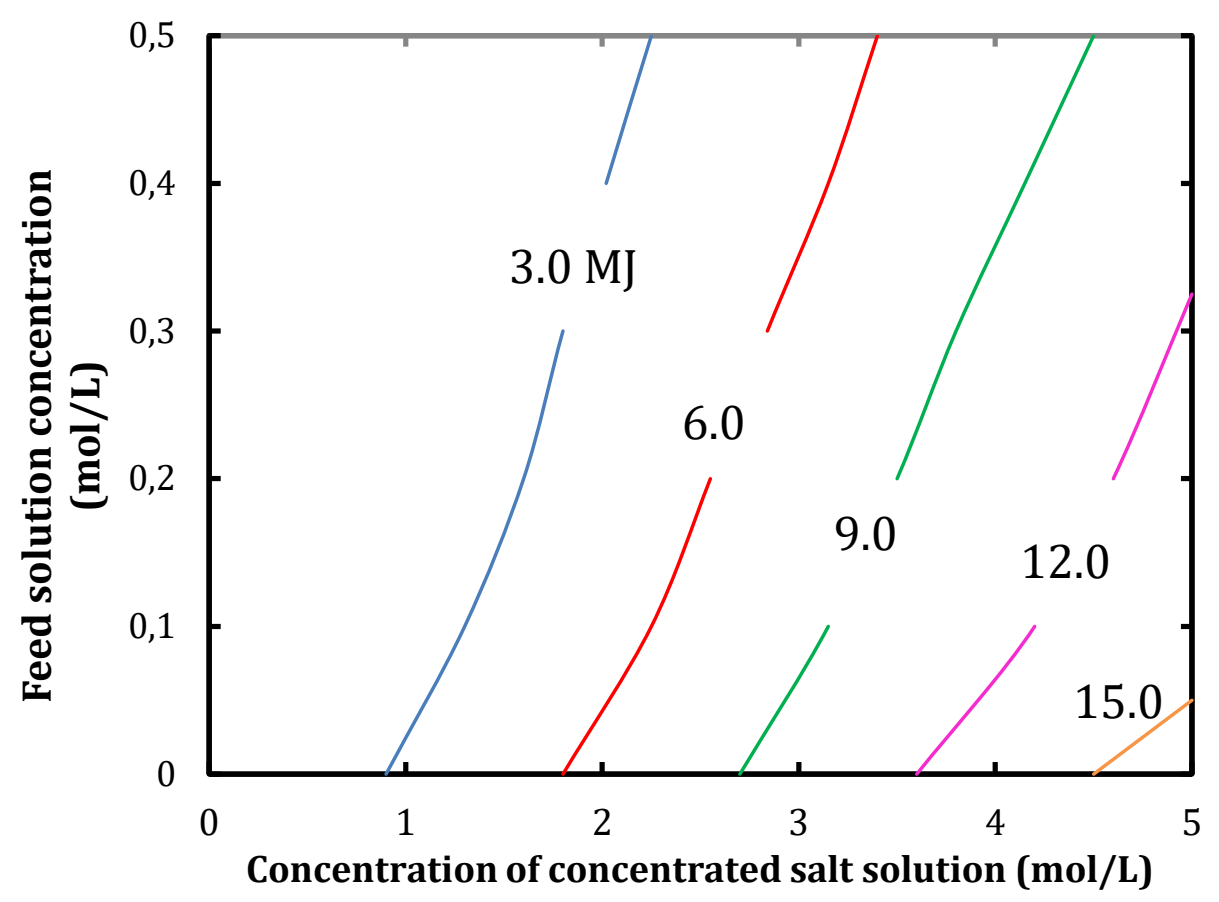

Fig. 2: Theoretically available amount of energy (MJ) from mixing $1 \mathrm{~m}^{3}$ of a diluted and $1 \mathrm{~m}^{3}$ of a concentrated sodium chloride solution $(T=293 \mathrm{~K})$. 


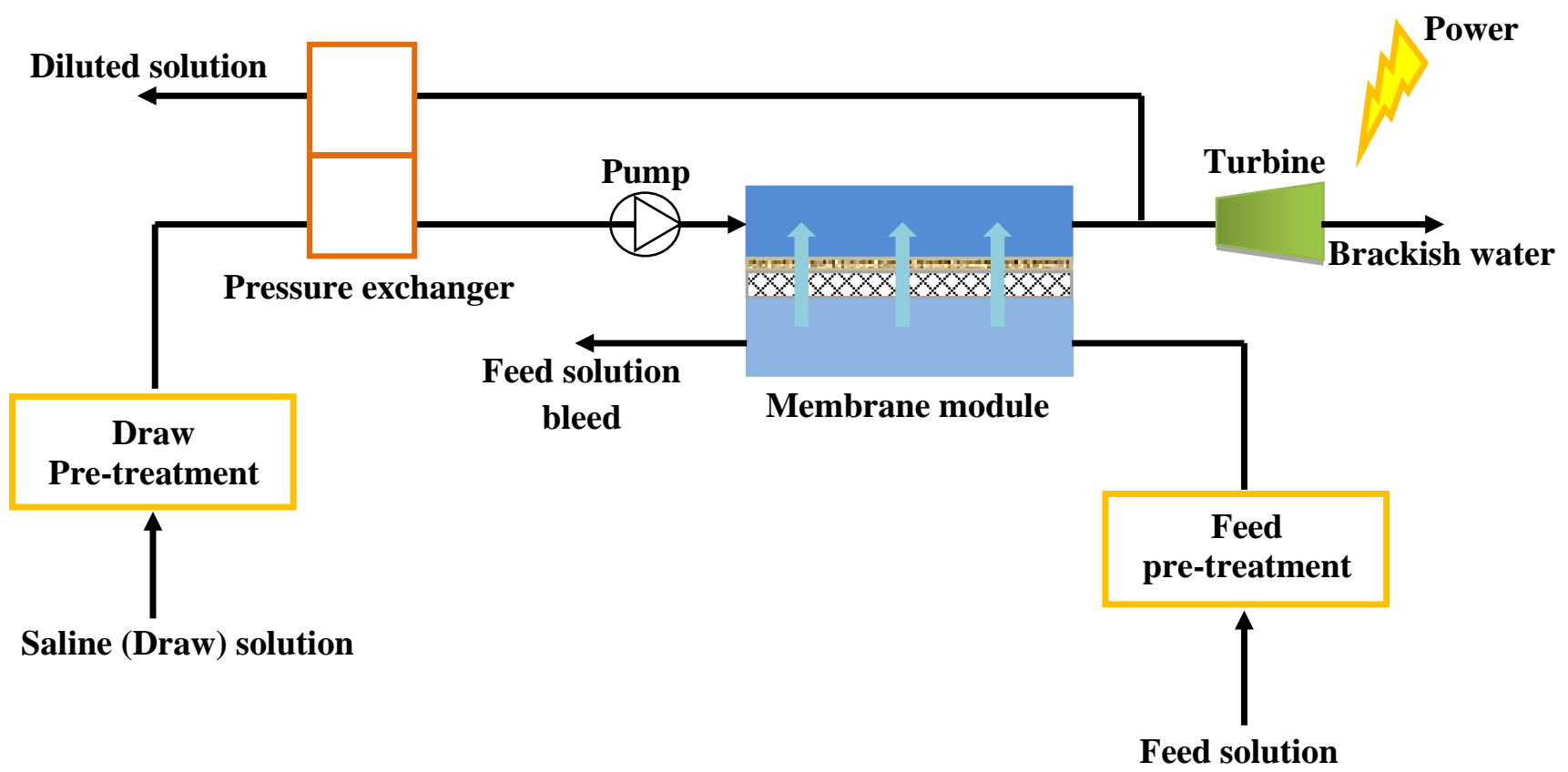

Fig. 3: Schematic of a PRO power plant.

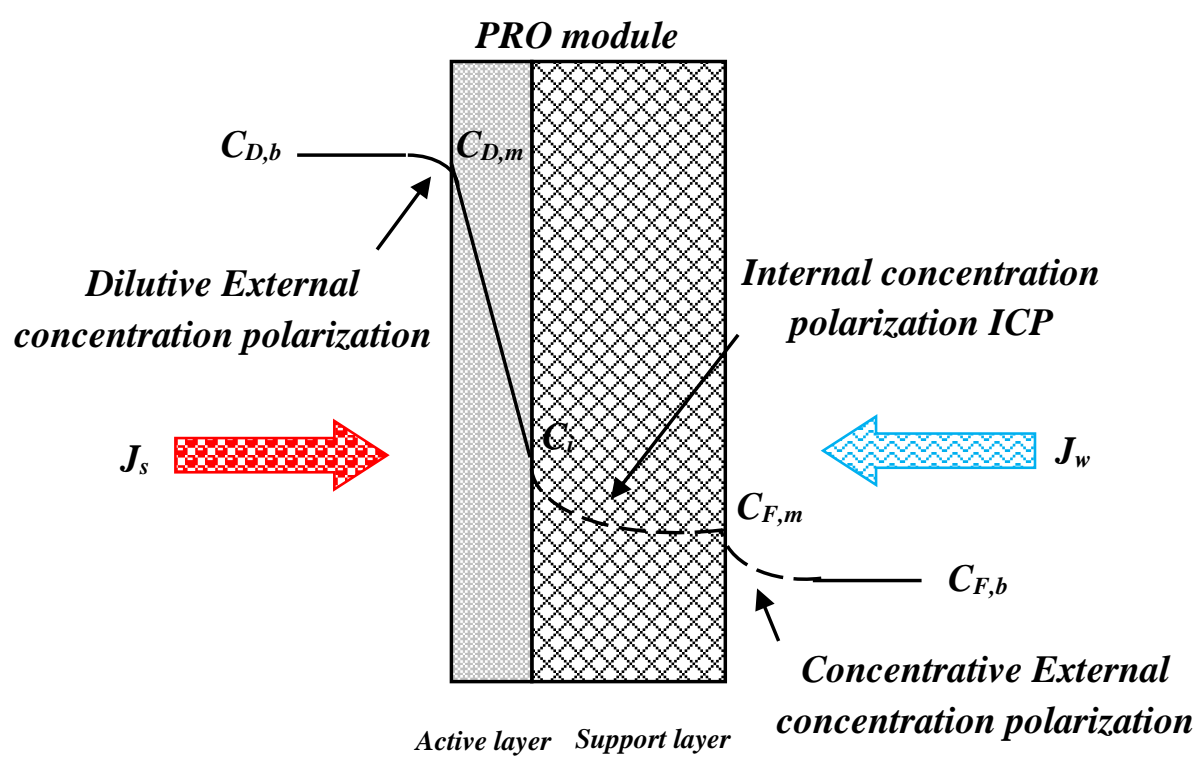

Fig. 4: schematic representation of the concentration profile over the membrane, and the directions of the water flux $J_{w}$ and the salt flux $J_{s}$ across a PRO membrane at steady state. ICP, Concentrative and Dilutive ECP are also shown here. 


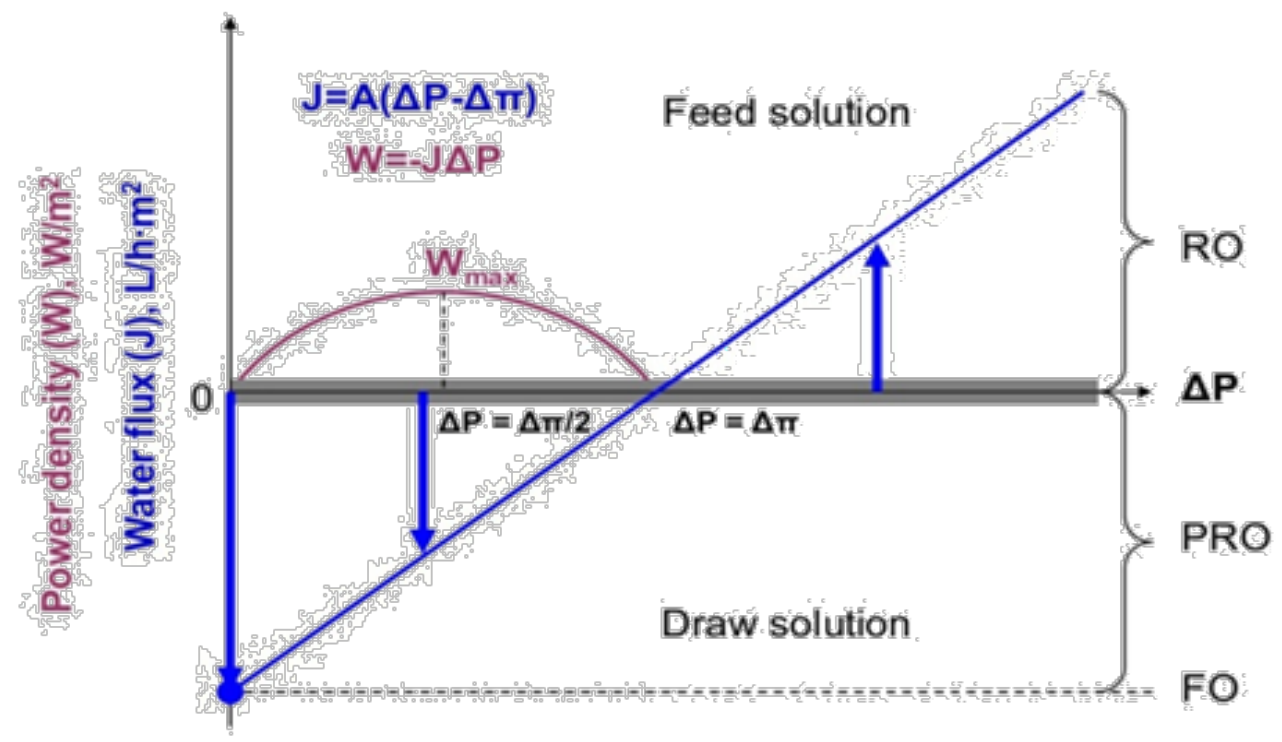

Fig. 5: Magnitude and direction of $J_{w}$ for FO, PRO, and RO and magnitude of $W$ for PRO in an ideal case.

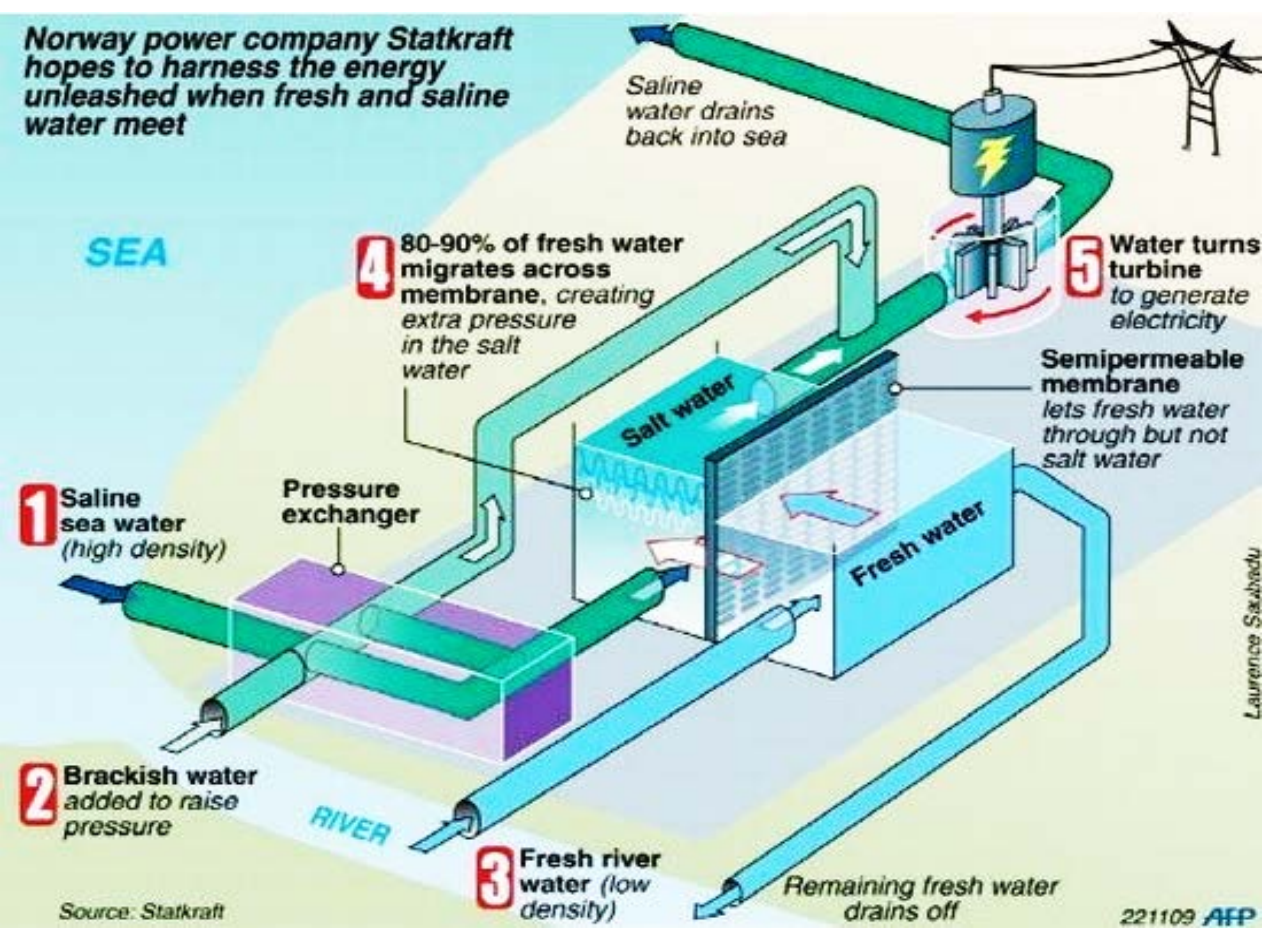

Fig. 6: Schematic diagram of the pilot PRO plant, constructed by Statkraft. 


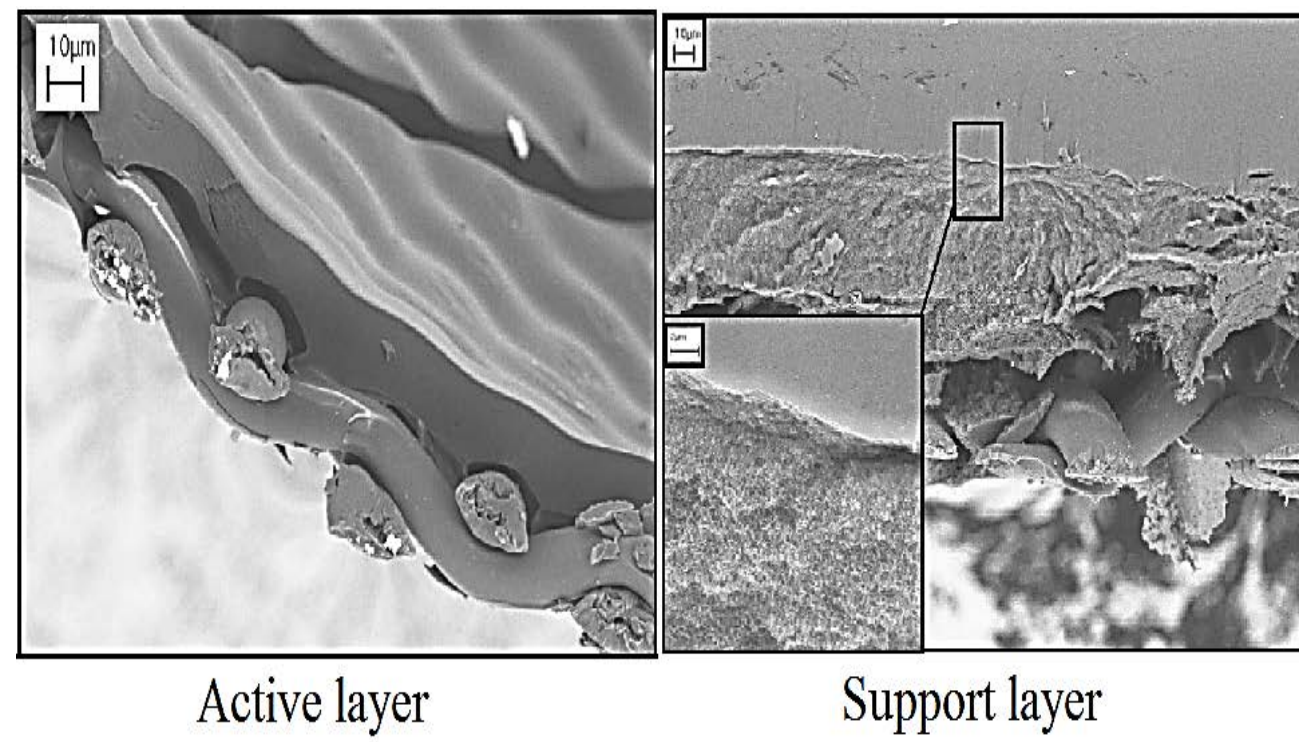

Fig. 7: Scanning Electron Microscope (SEM) photos of Cellulose Acetate PRO membrane developed by Schiestel.

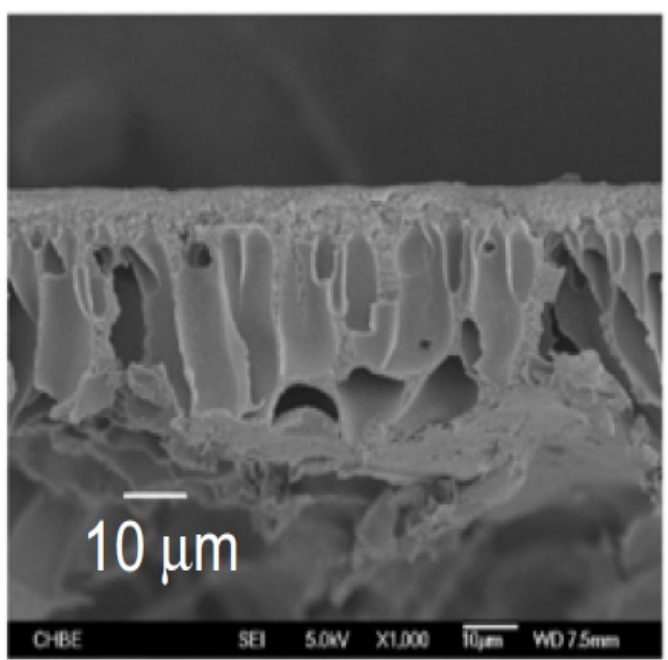

PAN $15 w t \%$

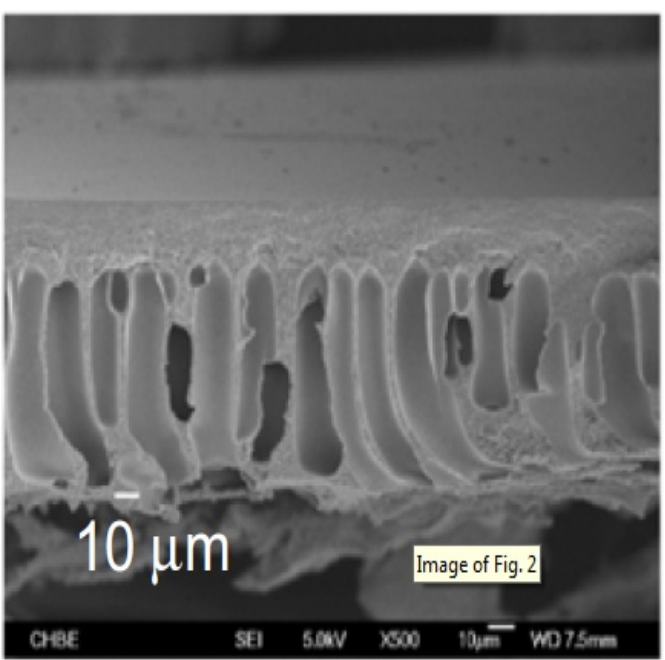

PAN $18 w t \%$

Fig. 8: SEM cross-section of the Polyamide/polyacrylonitrile (PAN) substrates made from two polymer concentrations developed by Zhang et al. (2013). 


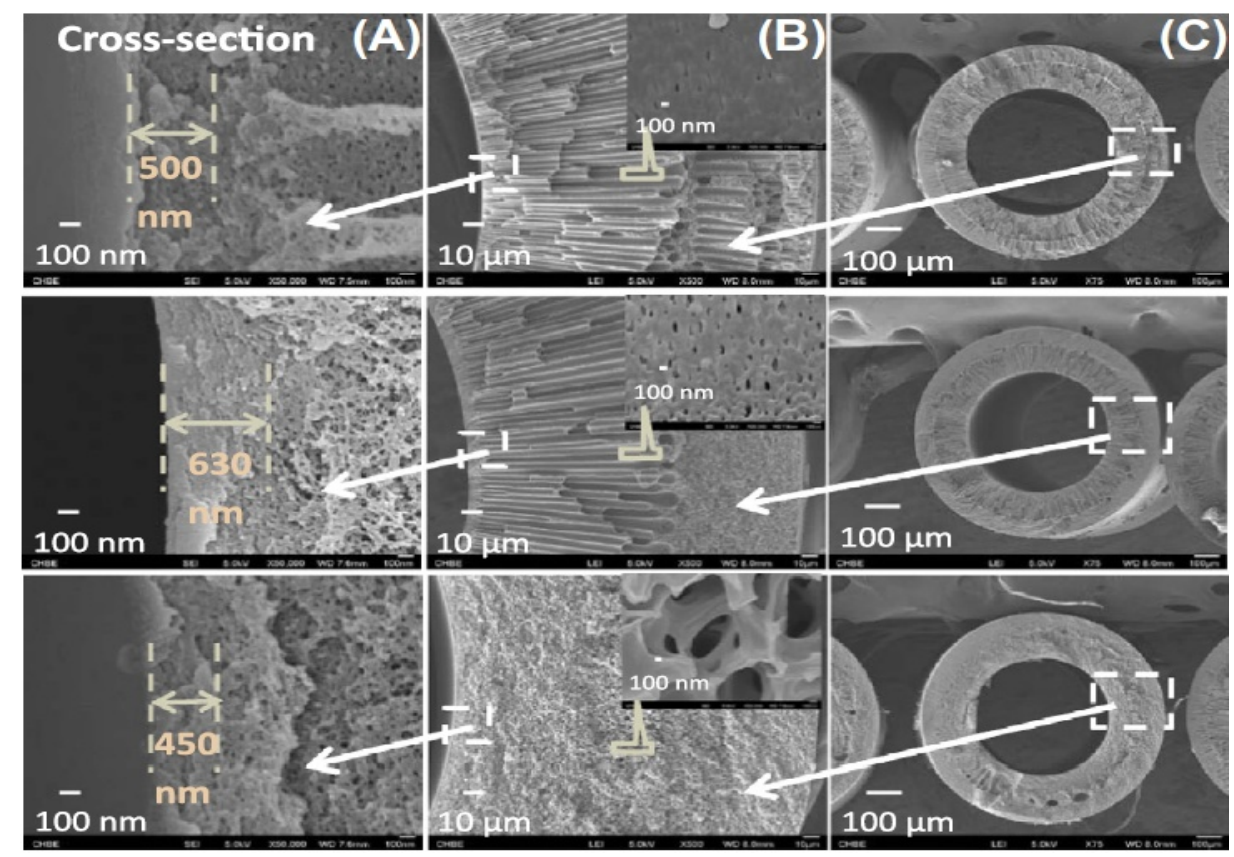

Fig. 9: SEM of the cross-section and surface morphologies of the PES hollow fiber supports developed by Zhang et al. (2014).

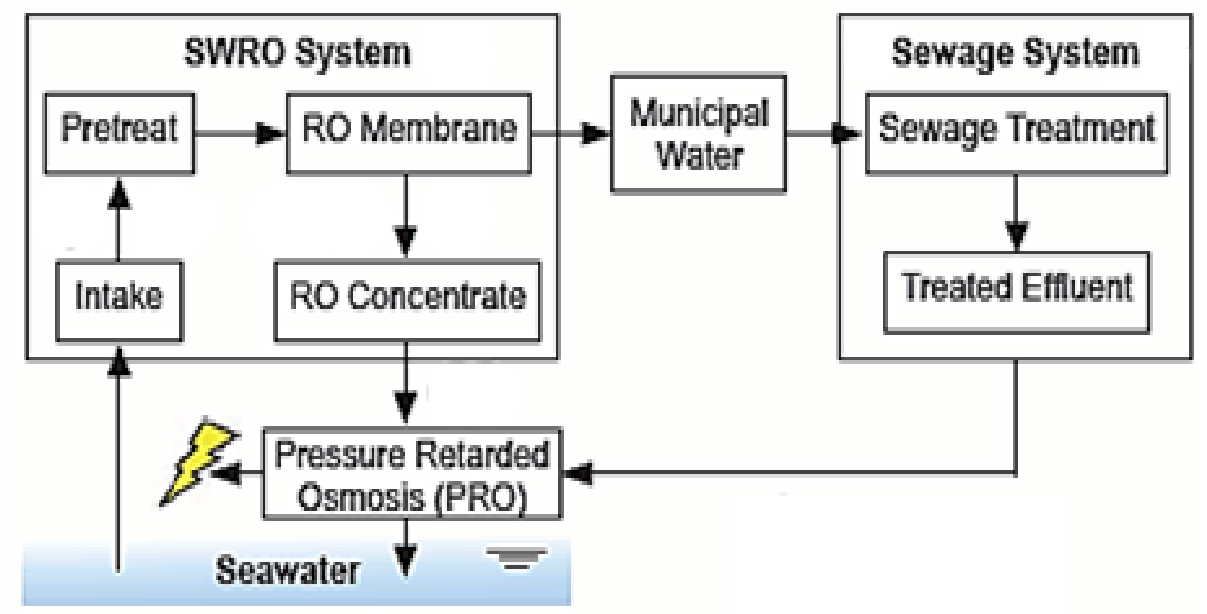

Fig. 10: Schematic of Mega-ton RO-PRO hybrid. 


\section{a) Hybrid 1}

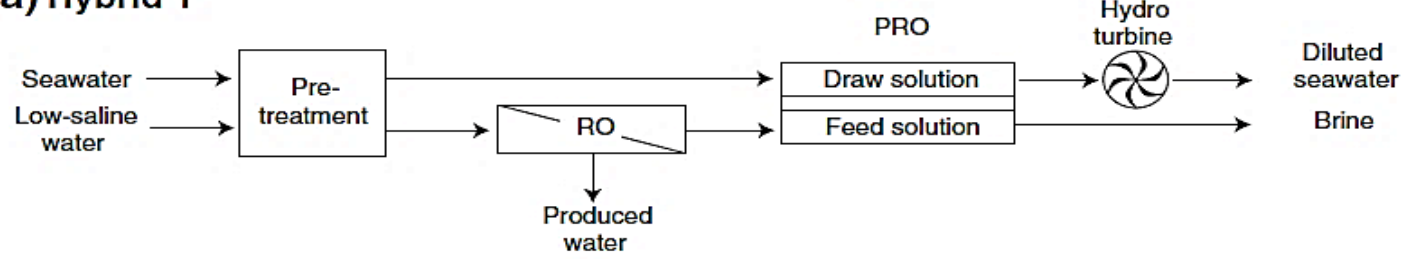

b) Hybrid 2

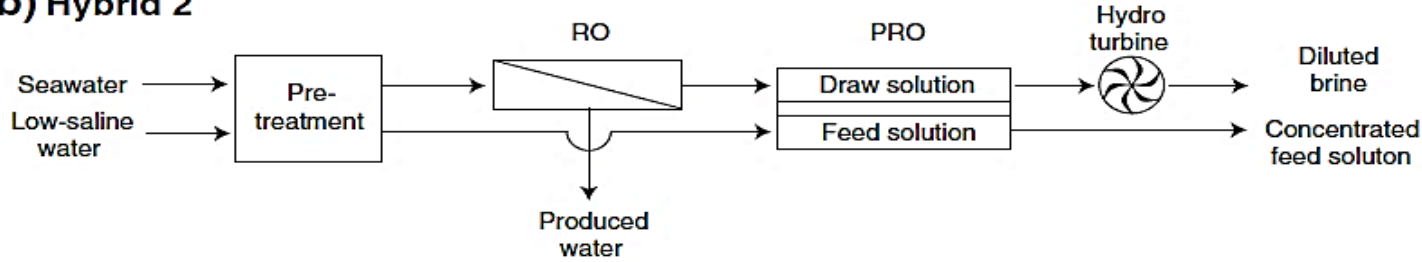

c) Hybrid 3

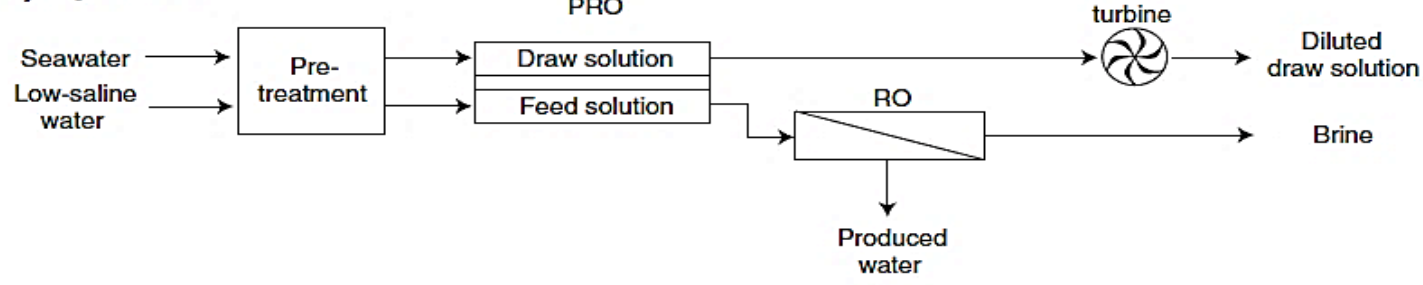

d) Hybrid 4
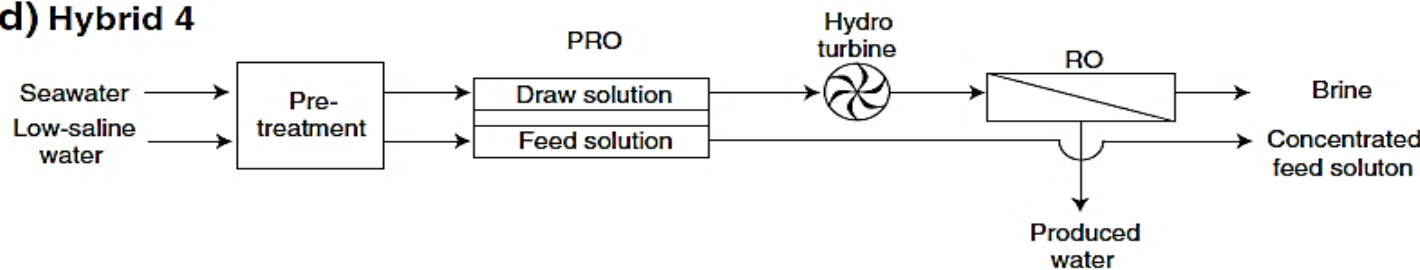

Fig. 11: Schematic of four RO-PRO hybrid systems proposed by Kim et al.

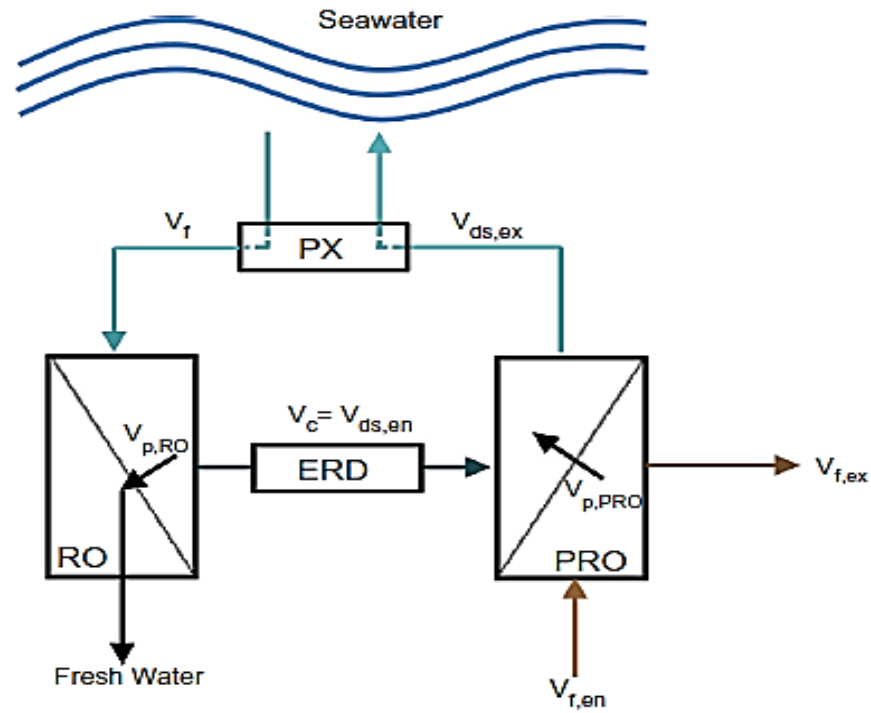

Fig. 12: Schematic of RO-PRO hybrid adopted by Achili et al. 


\section{Thermal Separation}

\section{Energy Production}

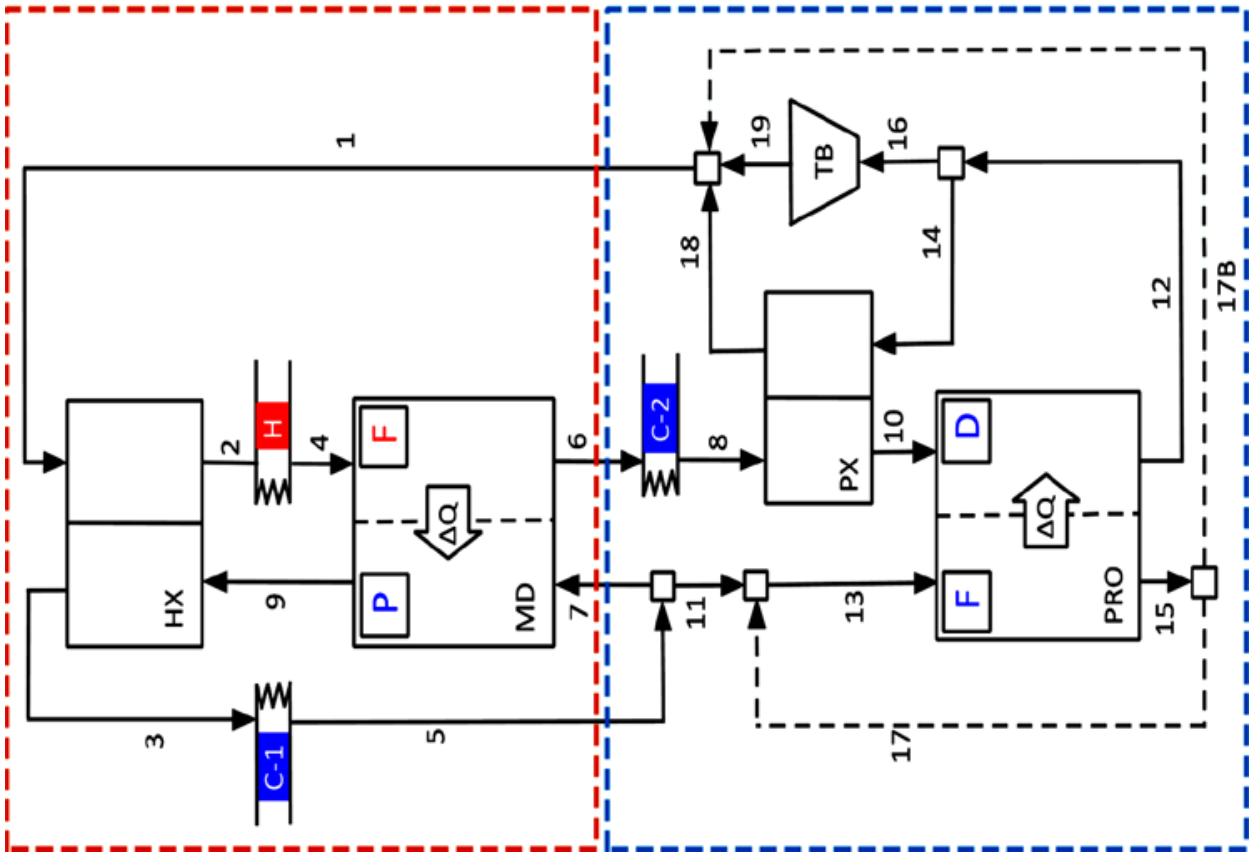

Fig. 13: Schematic diagram of a PRO-MD hybrid system for harvesting low-grade heat energy adopted by Lin et al. Heat exchanger (HX). Pressure exchanger. (PX) turbine (TB).

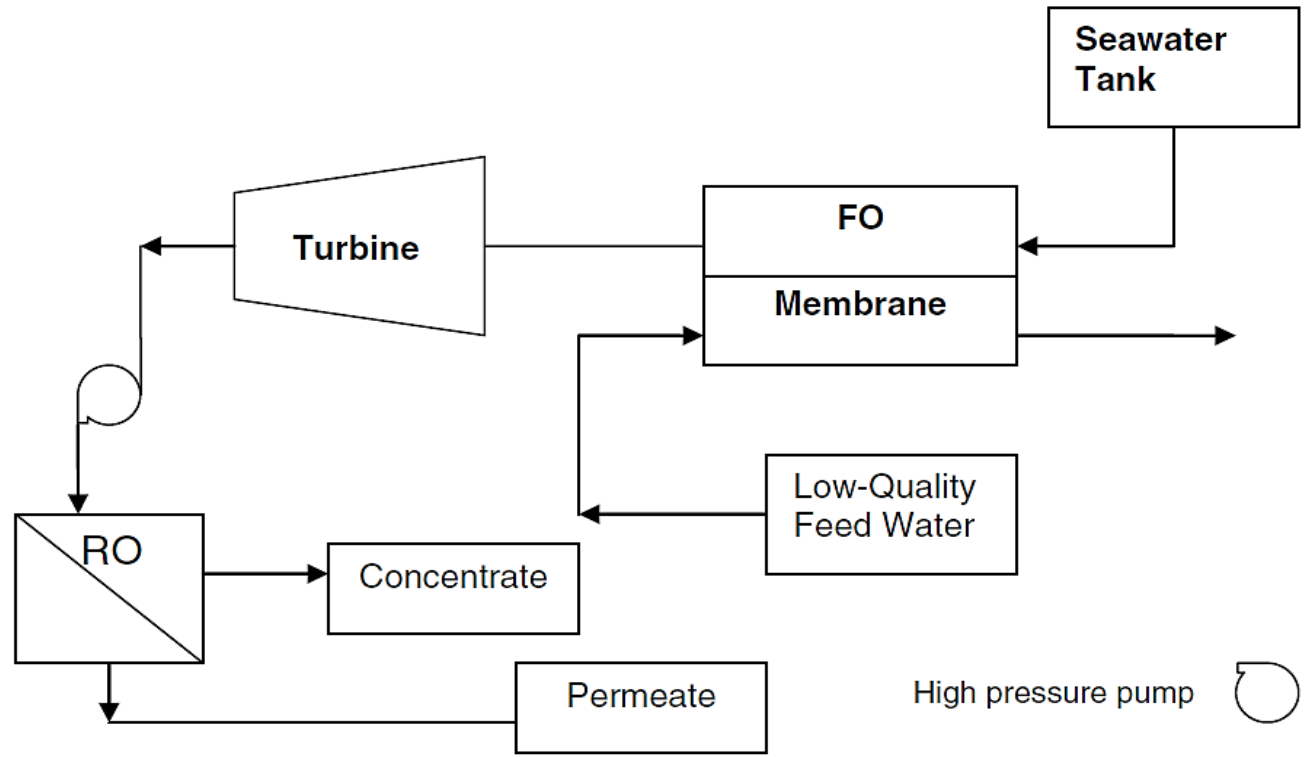

Fig. 14: Schematic diagram of the PRO-RO system for combined power generation and seawater desalination adopted by Altaee et al. 


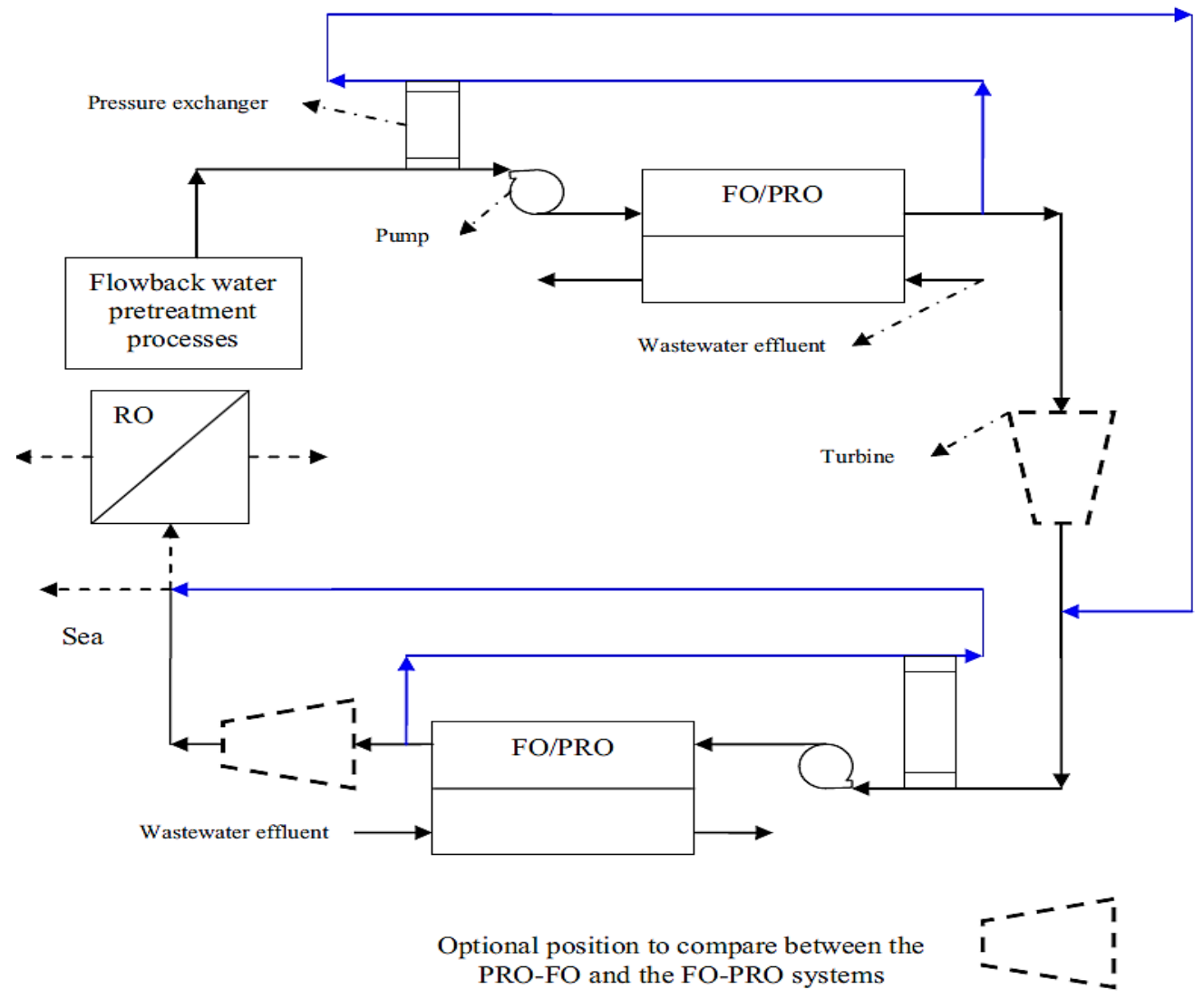

Fig. 15: Schematic diagram of the FO-PRO system for combined power generation and water treatment desalination adopted by Altaee et al.

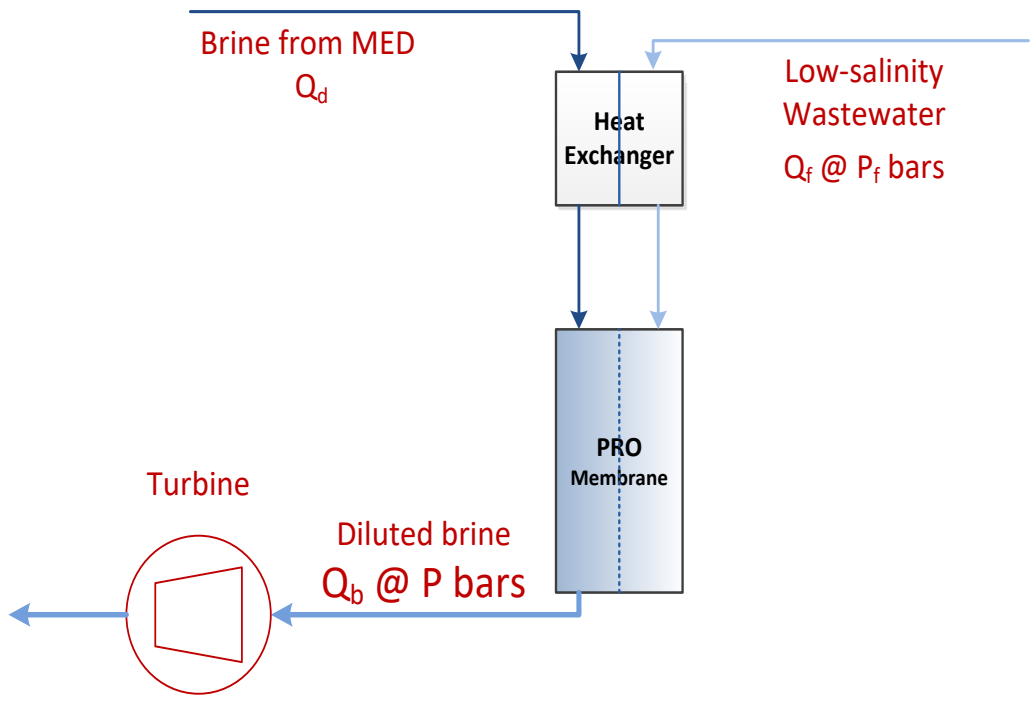

Figure 16: Basic Concept of the Pressure-Retarded Osmosis process for osmotic energy recovery of MED brines proposed by Touati et al. 


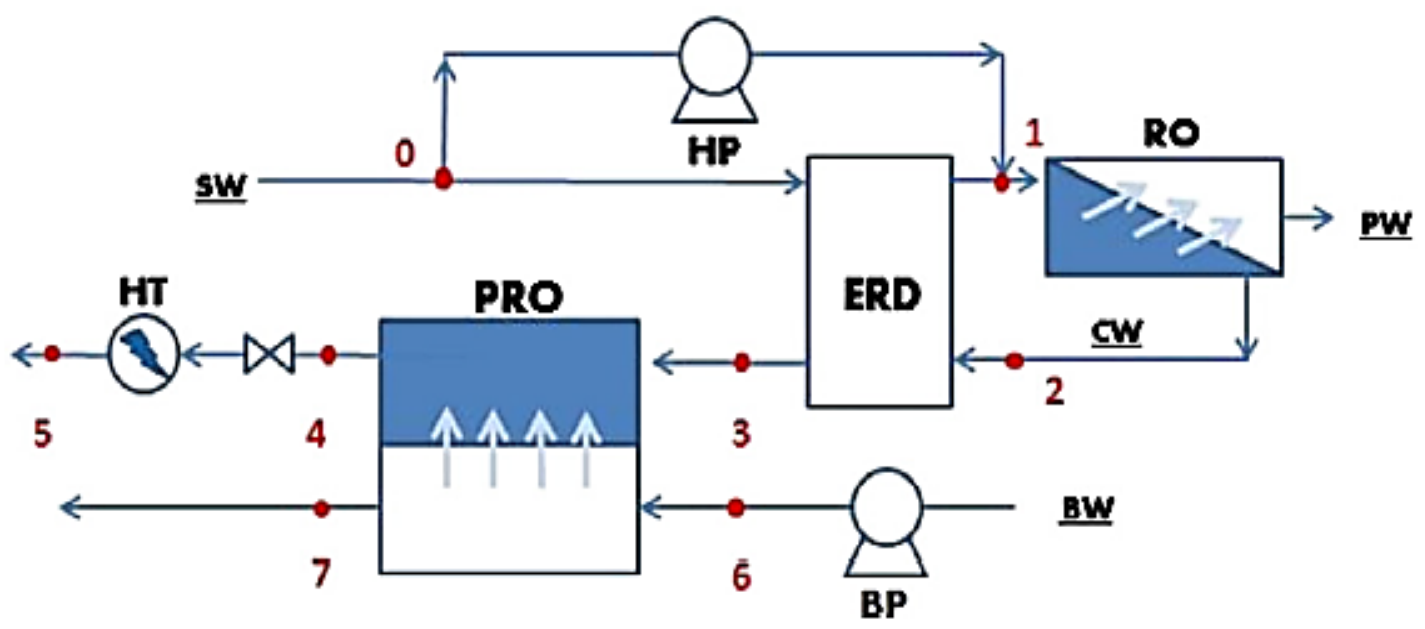

Fig 17: Schematic diagram of an RO-PRO hybrid system adopted by He et al.

(a) Configuration CDCF

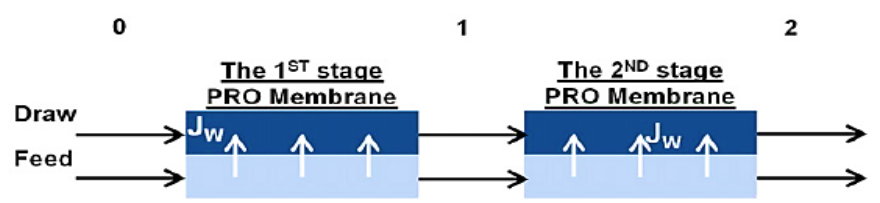

(b)

Configuration DDDF

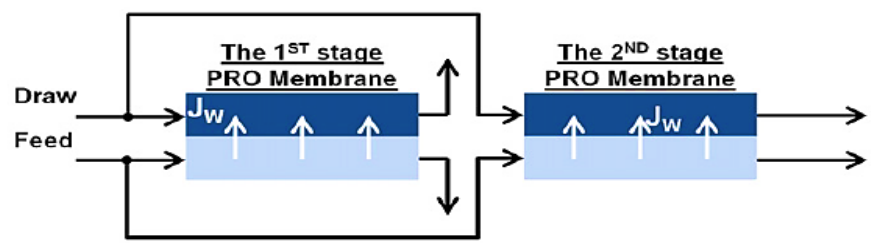

(c)

Configuration CDDF

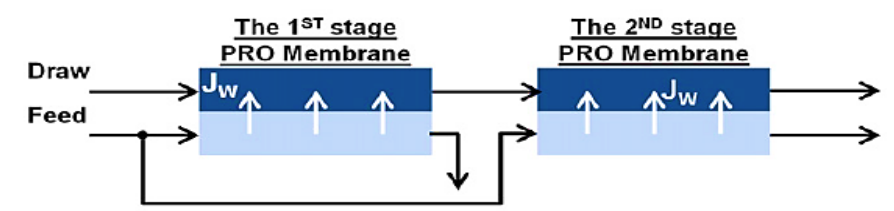

(d)

Configuration DDCF

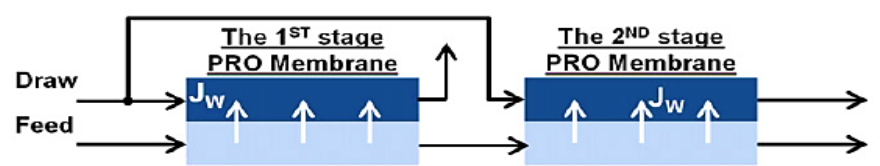

Fig. 18: Schematic diagram of the four possible configurations of the "TwoPRO" process proposed by He et al. 


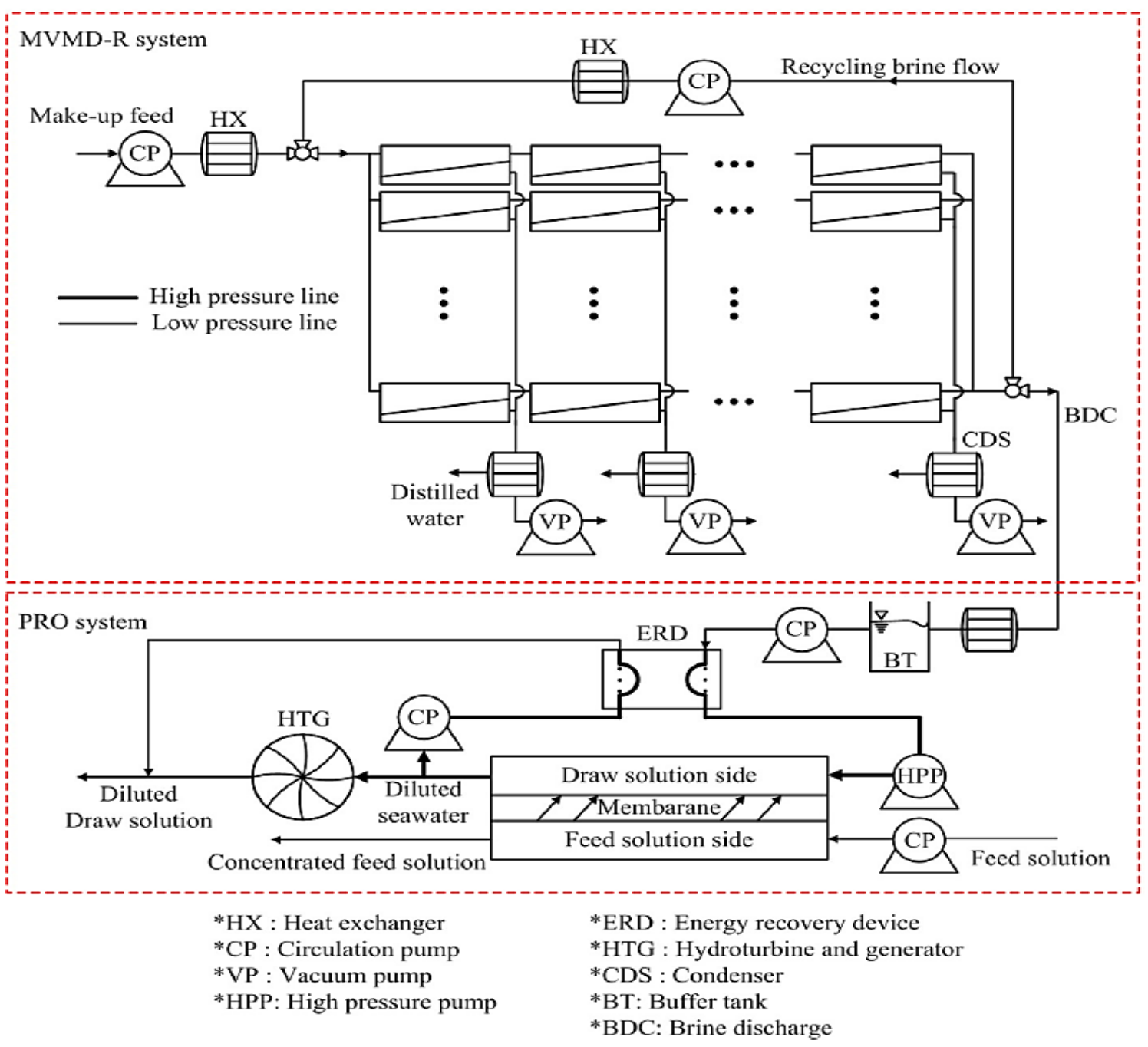

Fig. 19: The schematic of the hybrid MVMD-R-PRO system proposed by Lee et al.

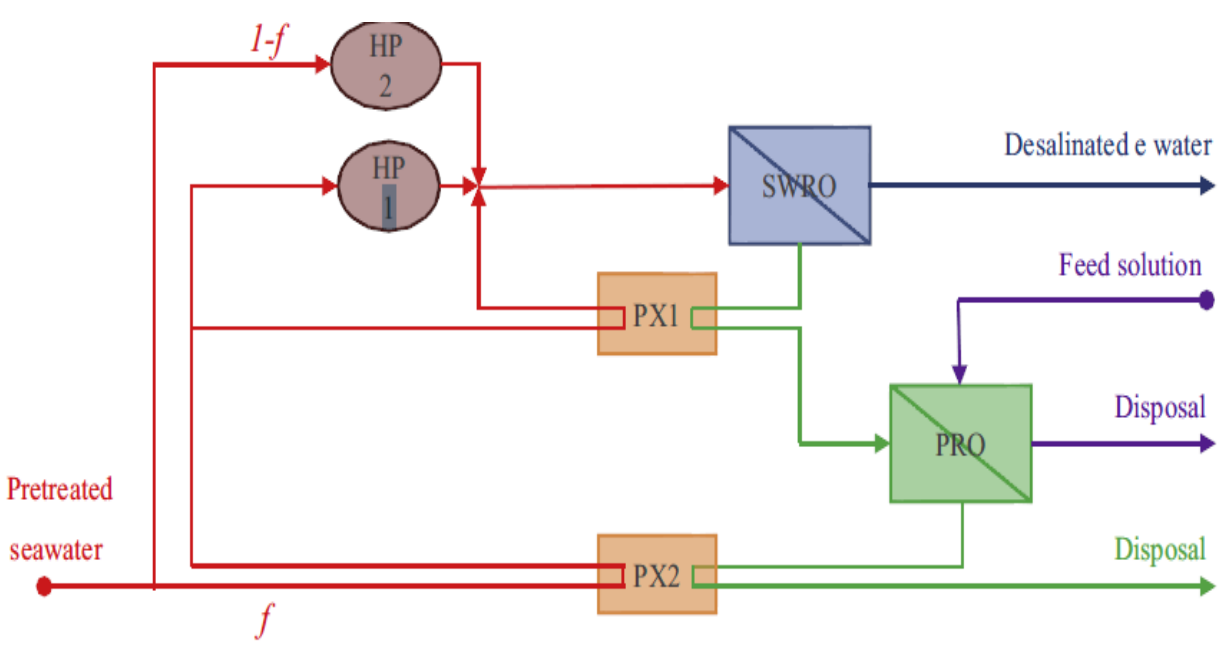

Fig. 20: SWRO-PRO process proposed by Wan et al. 2016 


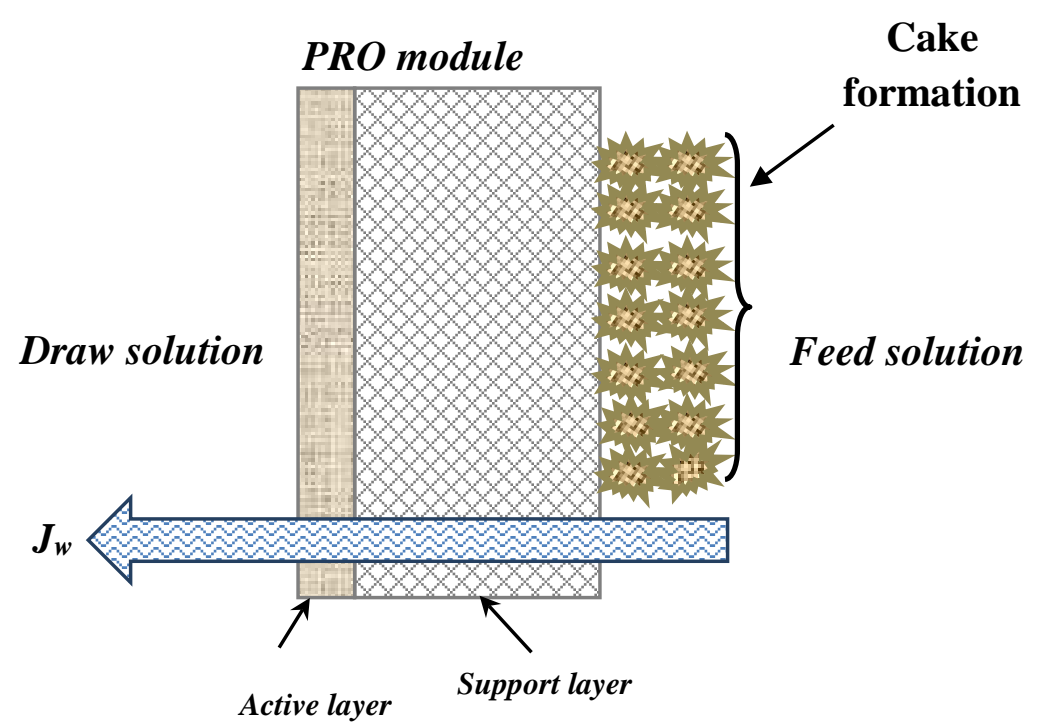

Fig. 21: NOM cake layer formation on the surface of PRO membrane porous layer.

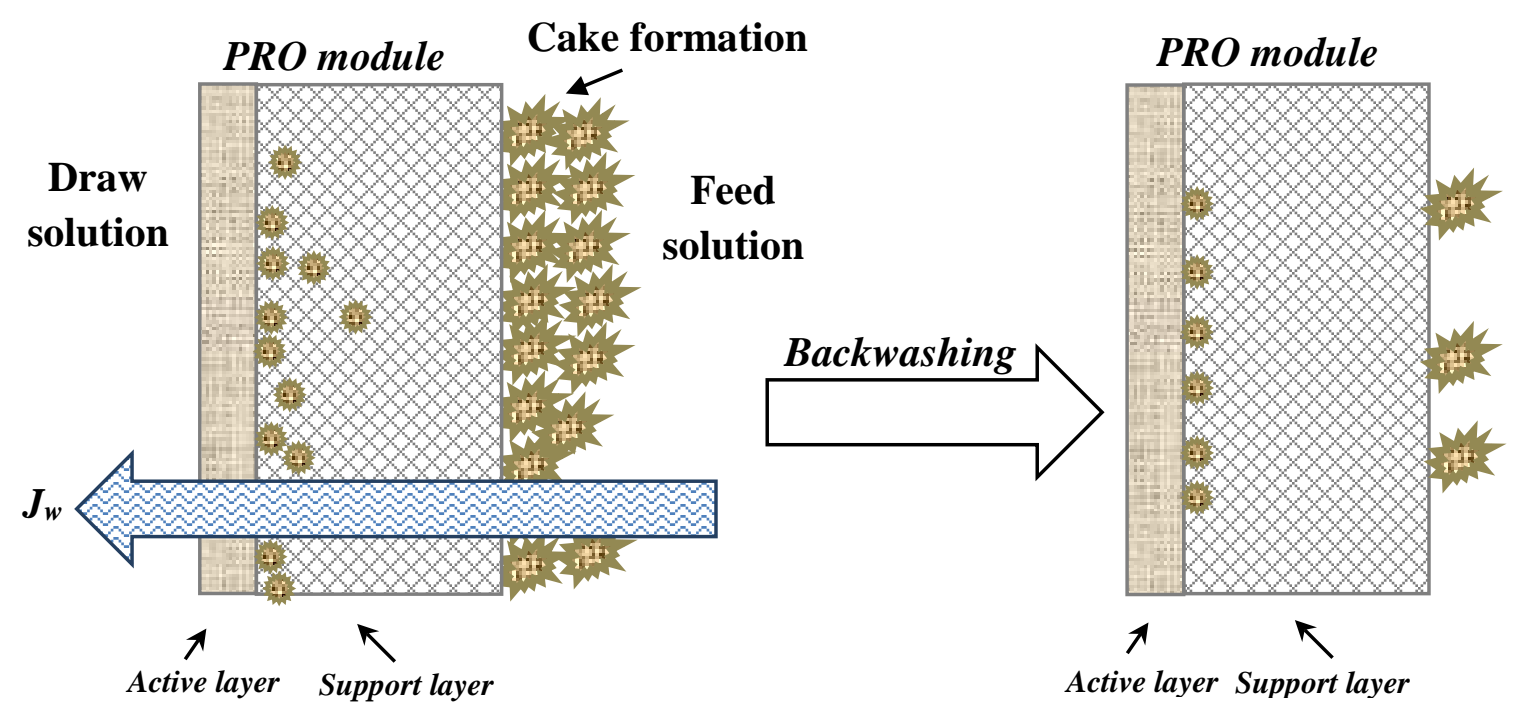

Fig. 22: Effect of backwashing on reducing NOM fouling in PRO membrane 


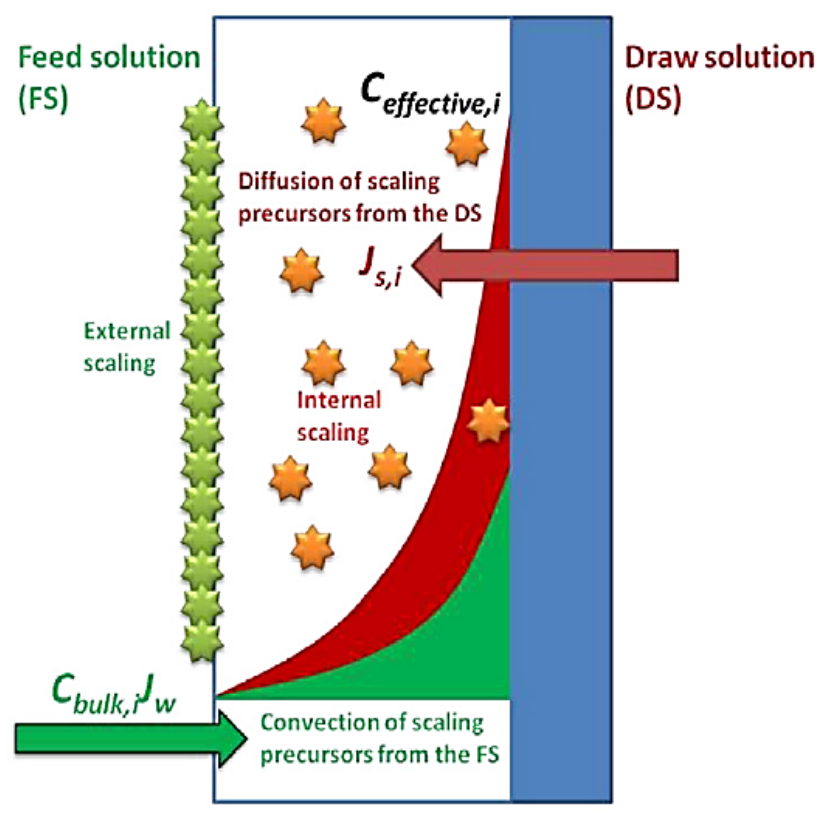

Fig. 23: PRO scaling mechanisms. The subscript (i) refers to the precursor (i). Zhang et al. (2014).

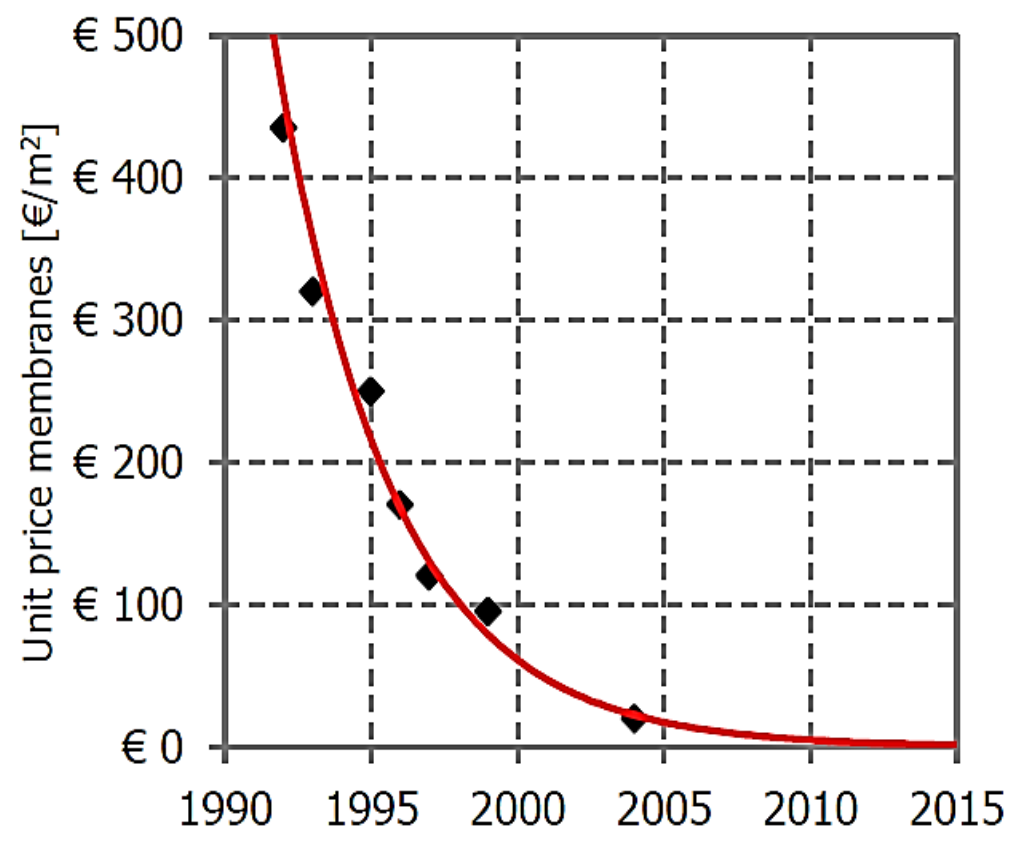

Fig. 24: Decrease of membrane price . 